\title{
Regulatory regions in natural transposable element insertions drive interindividual differences in response to immune challenges in Drosophila
}

\author{
Anna Ullastres ${ }^{\dagger}$, Miriam Merenciano ${ }^{\dagger}$ and Josefa González ${ }^{*}$ (1)
}

*Correspondence: josefa.gonzalez@ ibe.upf-csic.es

${ }^{\dagger}$ Anna Ullastres and Miriam Merenciano contributed equally to this work.

Institute of Evolutionary Biology (CSIC-Universitat Pompeu Fabra), Passeig Marítim de la Barceloneta 37-49, 08003 Barcelona, Spain

\begin{abstract}
Background: Variation in gene expression underlies interindividual variability in relevant traits including immune response. However, the genetic variation responsible for these gene expression changes remains largely unknown. Among the non-coding variants that could be relevant, transposable element insertions are promising candidates as they have been shown to be a rich and diverse source of cis-regulatory elements.

Results: In this work, we use a population genetics approach to identify transposable element insertions likely to increase the tolerance of Drosophila melanogaster to bacterial infection by affecting the expression of immune-related genes. We identify 12 insertions associated with allele-specific expression changes in immune-related genes. We experimentally validate three of these insertions including one likely to be acting as a silencer, one as an enhancer, and one with a dual role as enhancer and promoter. The direction in the change of gene expression associated with the presence of several of these insertions is consistent with an increased survival to infection. Indeed, for one of the insertions, we show that this is the case by analyzing both natural populations and CRISPR/Cas9 mutants in which the insertion is deleted from its native genomic context.
\end{abstract}

Conclusions: We show that transposable elements contribute to gene expression variation in response to infection in D. melanogaster and that this variation is likely to affect their survival capacity. Because the role of transposable elements as regulatory elements is not restricted to Drosophila, transposable elements are likely to play a role in immune response in other organisms as well.

Keywords: Allele-specific expression, Gut immunity, Adaptation, Regulatory elements, Enhancer, Silencer

(c) The Author(s). 2021 Open Access This article is licensed under a Creative Commons Attribution 4.0 International License, which permits use, sharing, adaptation, distribution and reproduction in any medium or format, as long as you give appropriate credit to the original author(s) and the source, provide a link to the Creative Commons licence, and indicate if changes were made. The images or other third party material in this article are included in the article's Creative Commons licence, unless indicated otherwise in a credit line to the material. If material is not included in the article's Creative Commons licence and your intended use is not permitted by statutory regulation or exceeds the permitted use, you will need to obtain permission directly from the copyright holder. To view a copy of this licence, visit http://creativecommons.org/licenses/by/4.0/. The Creative Commons Public Domain Dedication waiver (http://creativecommons.org/publicdomain/zero/1.0/) applies to the data made available in this article, unless otherwise stated in a credit line to the data. 


\section{Background}

Gene expression changes occur across developmental stages and cell types and in response to external stimuli and disease. Identifying the genetic variation underlying context-dependent differences in gene expression is thus essential to understand organism's development and functioning [1-3]. Experimental and computational efforts aimed at identifying gene regulatory elements are biased towards activating elements, namely enhancers and promoters, while silencing regulatory elements are less-studied. Moreover, recent advances suggest that the classical definition of regulatory elements needs to be updated. Activating regulatory elements may have both enhancer and promoter functions and silencers may act as enhancers in alternate cellular contexts [2, 4, 5]. Another bias of the current approaches is that they are mostly focused on the analysis of single nucleotide variants [6]. However, transposable elements (TEs) are also known to be a rich and diverse source of cis-regulatory elements [7-12].

TEs are repetitive DNA sequences with the ability to move along the genome [13]. They can disperse promoters and enhancers that increase gene expression levels [14, 15], and they can also silence gene expression by spreading heterochromatin formation and stalling Pol II elongation $[12,16]$. TEs have also been documented to function as boundary elements or insulators and to contribute to non-coding regulatory sequences that modify gene expression post-transcriptionally $[9,11]$. In addition to providing cis-regulatory elements to individual genes, TEs also have an impact on gene regulation at a genome-wide level in different organisms such as human, mouse, and D. melanogaster [17-26]. The genome-wide contribution of TEs to gene regulation has been studied in several relevant phenotypes such as development, response to xenobiotics, immune response, and disease [23, 27-29]. While there are several studies highlighting the potential role of TE insertions in the regulation of the immune response [30-32], whether TEs are more often recruited to play a role in immune response remains speculative [33].

Innate immunity is the first barrier against infections, and many species rely solely on this response to cope with pathogens [34,35]. One of the most likely infection routes occurring in nature is oral infection, and the gut epithelium is the first barrier that bacteria encounter in the organism [36, 37]. However, the gut immune response is still not completely understood, and it is likely more complex than the systemic immune response [36, 38-40]. Variation in gene expression has been shown to underlay interindividual variability in immune responses in several organisms including humans [41-45]. In D. melanogaster, gut immunocompetence variation was analyzed in 140 strains, and small but systematic differences in gene expression were found between resistant and susceptible strains to Pseudomonas entomophila, a natural pathogen of this species [41, 46]. However, the causal mutations responsible for these expression changes remain largely unknown $[45,47,48]$. The ability to carry out in vivo enhancer assays and CRISPR/Cas9 mediated genomic deletions makes $D$. melanogaster a prime choice to study the role of TEs in immune-related processes.

In this work, we aimed at identifying transposable element variants that could be contributing to the ability of $D$. melanogaster populations to cope with immune challenges. While the identification of regulatory variants is often based on sequence analysis, we used a population genetics approach in which we look for TE insertions likely to be evolving under positive selection. We then performed allele-specific expression analysis to identify which of the candidate TE insertions were associated with changes 
in gene expression. Finally, we combined multiple experimental techniques, including CRISPR/Cas9, to provide additional evidence of functionality for a subset of the identified candidate TE insertions.

\section{Results}

Nineteen natural transposable element insertions present at high population frequencies are located nearby genes with immune-related functions

To identify polymorphic transposable elements (TEs) that are likely to be adaptive and to play a role in immune response, we first looked for insertions present at both high population frequencies and in genomic regions with recombination rate larger than zero (see the "Methods" section). The rationale for this screening is as follows: (i) if a mutation is adaptive, that particular mutation is expected to be present at high population frequencies; and (ii) although slightly deleterious or neutral mutations could also increase in frequency in populations, this is less likely in regions with recombination rate larger than zero because the efficiency of selection in these regions is high [49]. We analyzed the frequency of $831 \mathrm{TE}$ insertions located in regions with recombination rates larger than zero, in four natural populations: Siavonga (Zambia), Stockholm (Sweden), Bari (Italy), and North Carolina (USA) (Additional file $1 \mathrm{~A}$ and $1 \mathrm{~B}$, see the "Methods" section) [50-52]. Although the majority of these $831 \mathrm{TE}$ insertions are present in the reference genome, we also included in our analysis 23 de novo TE insertions [51] (see the "Methods" section). Overall, we identified $128 \mathrm{TE}$ insertions present at $>10 \%$ frequency in at least one of the four populations analyzed (Additional file $1 \mathrm{C}$, see the "Methods" section).

We then surveyed the literature for any functional information available for the genes located nearby each of these 128 TEs (Additional file 1D). We found that 19 of these TEs were associated with 21 immune-related genes (Table 1). The functional evidence for the majority of these genes comes from transcriptional response to infection (12 genes), infection survival experiments (five genes), or both (two genes; Table 1). The other two genes, TM4SF and ken, are also involved in immune response. TM4SF is a member of the tetraspanin transmembrane proteins, which modulate immune signaling in Drosophila [53], and ken is a member of the JAK-STAT signaling pathway involved in immune response [54]. To provide further evidence for the role of these genes in immune-related functions, we performed infection survival experiments with Pseudomonas entomophila for five genes for which survival experiments were not previously available (CG2233, ken, CG8008, TM4SF, and CG10943), and for three genes for which survival experiments were performed using a different pathogen (NUCB1, Bin1, and $c b x$ ). P. entomophila [46] is a natural D. melanogaster pathogen, and thus experiments with these gram-negative bacteria have the potential to identify specialized immune responses derived from antagonistic co-evolution [55]. To perform the infection survival experiments, we used a mixture of RNAi knockdown lines, gene disruption lines, and overexpression lines, and when possible, we used two different genetic backgrounds (Fig. 1, Additional file 2A). We first confirmed that the RNAi knockdown lines, gene disruption lines, and overexpression lines indeed showed changes in expression of the target genes (Additional file 2A and 2B; see the "Methods" section). We found that changes in expression for seven of the eight genes tested were associated with differences in survival after infection: expression 
Table 1 Candidate TEs located nearby immune-related genes. TE length is indicated as full-length $(F L)$ or truncated $(T)$. In the case of truncated elements, whether the insertion is a solo LTR, a TIR or $5^{\prime}$ truncated $\left(5^{\prime}\right)$ is also indicated. NS, not significant. NA, not analyzed

\begin{tabular}{|c|c|c|c|c|c|c|}
\hline $\mathrm{TE}$ & $\begin{array}{l}\text { TE } \\
\text { family } \\
\text { (class) }\end{array}$ & $\begin{array}{l}\text { TE start } \\
\text { position }\end{array}$ & $\begin{array}{l}\text { TE } \\
\text { length }\end{array}$ & $\begin{array}{l}\text { Evidences } \\
\text { of } \\
\text { selection }\end{array}$ & $\begin{array}{l}\text { Gene } \\
\text { (position) }\end{array}$ & Immune-related evidence \\
\hline FBti0019457 & $\begin{array}{l}\text { pogo } \\
\text { (DNA) }\end{array}$ & $\begin{array}{l}3 R: \\
29760415\end{array}$ & $\begin{array}{l}1146 \\
\text { bp (T: } \\
\text { TIR) }\end{array}$ & Fst, nSL [52] & $\begin{array}{l}\text { kay (4434 } \\
\text { bp 5') }\end{array}$ & $\begin{array}{l}\text { Expression. Component of the JNK } \\
\text { pathway, essential for antimicrobial } \\
\text { peptide release [56, 57]. Upregulated in } \\
\text { imd and bsk mutant LPS-induced S2 } \\
\text { cells, and downregulated in Rel mutants } \\
\text { [58]. Upregulated in larvae infected with } \\
\text { P. entomophila (gram-negative) [46], and } \\
\text { after } 4 \text { h of infection with P. entomophila } \\
\text { [41] }\end{array}$ \\
\hline
\end{tabular}

$\begin{array}{llllll}\text { FBti0020046 } & \text { Doc } & 3 \mathrm{L:} & 2305 & \text { Allele age } & \text { Jon65Aiv } \\ & \text { (non-LTR) } & 6040416 & \mathrm{bp}(\mathrm{T}: & {[59]} & (281 \mathrm{bp} \\ & & & \left.5^{\prime}\right) & & \left.3^{\prime}\right)\end{array}$

FBti0020057 BS (non- $3 \mathrm{~L}: \quad 126 \mathrm{bp} \quad \mathrm{H12}, \mathrm{nSL}$ $\begin{array}{llll}\text { LTR) } & 7130011 & \text { (T: 5') [52] }\end{array}$

CG15829 (338 bp bp (T:

LTR)

$\begin{array}{lllll}\text { FBti0019381 Juan } & \text { 3R: } & 2995 & \text { NS } \\ & \text { (non-LTR) } & 15132112 & \text { bp (T: } & \\ & & \left.5^{\prime}\right) & \\ \text { FBti0019602 } & \text { Juan } & \text { X: } & 4249 & \text { NS } \\ & \text { (non-LTR) } & 8031495 & \text { bp (FL) } & \end{array}$

FBti0061105

G5 (non- 2R:

LTR

FBti0062242 BS (non-

LTR)

$\operatorname{tdn} 4$

BS (non- 2R:

800 bp NA

LTR)

1880787

(T: 5')

$51 \mathrm{bp} \quad$ NS

(T: $5^{\prime}$

02 bp NS
3')

CG8628

(739 bp

5')

CG8008

136 bp 3') [41].

Expression. Upregulated after septic injury with mixed bacteria: M. luteus (gram-positive) and E. coli (gramnegative) [60]. Downregulated after $4 \mathrm{~h}$ of infection with $P$. entomophila [41]. Downregulated after oral infection with the avirulent gacA P. entomophila [61].

Expression. Upregulated after infection by septic injury with mixed bacteria (gram-positive and gram-negative), and regulated by Rel [60]. Upregulated after $4 \mathrm{~h}$ of infection with $P$. entomophila [41]. Upregulated in transgenic flies expressing a SINV replicon (alphavirus) [62].

Expression. Upregulated in microbiota associated flies vs. germ free flies [63], after infection with several pathogens (gram-positive and gram-negative, fungi, protozoa) [64], and downregulated after $4 \mathrm{~h}$ of infection with P. entomophila [41].

Expression. Induced by LPS (gramnegative) in an IKK-dependent manner in S2 cell cultures [65]. Upregulated after E. coli (gram-negative) infection in S2 cells [66].

CG42788

(180 bp

5')

Expression. Downregulated in response to $P$. rettgeri (gram-negative) infection in females [67].

CG2233 Expression. Downregulated in PEBP

(12 bp 3') mutant L3 larvae, which are more resistant to $M$. luteus (gram-positive) and E. coli (gram-negative) infection [68]. Latitudinal expression differentiation after infection with E. coli and M. luteus mix in temperate vs. tropical populations [69].

Dscam 1 Expression. Required in hemocytes for (46 bp 3') efficient phagocytosis and binds to $E$. coli (gram-negative) [70].

Pnr (3' Expression. pnr is a modifier of the Toll UTR) pathway and RNAi mutants show Imd pathway hyperactivation when infected with E. cloacae (gram-negative) and $M$. luteus and E. faecalis (gram-positive) [71].

CG15096 Expression. Downregulated in Oregon (479 bp R and Rel-mutant flies with microbiota 3) compared to axenic flies [72], and after P. entomophila infection [41].

CG10943 Expression. Upregulated in Oregon R 
Table 1 Candidate TEs located nearby immune-related genes. TE length is indicated as full-length $(F L)$ or truncated $(T)$. In the case of truncated elements, whether the insertion is a solo LTR, a TIR or $5^{\prime}$ truncated $\left(5^{\prime}\right)$ is also indicated. NS, not significant. NA, not analyzed (Continued)

\begin{tabular}{|c|c|c|c|c|c|c|}
\hline$\overline{T E}$ & $\begin{array}{l}\text { TE } \\
\text { family } \\
\text { (class) }\end{array}$ & $\begin{array}{l}\text { TE start } \\
\text { position }\end{array}$ & $\begin{array}{l}\text { TE } \\
\text { length }\end{array}$ & $\begin{array}{l}\text { Evidences } \\
\text { of } \\
\text { selection }\end{array}$ & $\begin{array}{l}\text { Gene } \\
\text { (position) }\end{array}$ & Immune-related evidence \\
\hline & (LTR) & 12863675 & $\mathrm{bp}(\mathrm{FL})$ & & $\begin{array}{l}(816 \mathrm{bp} \\
\left.5^{\prime}\right)\end{array}$ & $\begin{array}{l}\text { and Rel-mutant flies with microbiota } \\
\text { compared to axenic flies [72], } 24 \mathrm{~h} \text { after } \\
\text { infection with } O \text {. muscaedomesticae } \\
\text { (protozoan) [64], and after } P \text {. } \\
\text { entomophila infection [41]. }\end{array}$ \\
\hline $\operatorname{tdn} 17$ & $\begin{array}{l}\text { pogo } \\
\text { (DNA) }\end{array}$ & $\begin{array}{l}X: \\
21399382\end{array}$ & $\begin{array}{l}2067 \\
\mathrm{bp}(\mathrm{FL})\end{array}$ & NA & $\begin{array}{l}\text { Ics }(2,067 \\
\left.\text { bp } 5^{\prime}\right)\end{array}$ & $\begin{array}{l}\text { Expression. Involved in virus response, } \\
\text { downregulated in males infected with } \\
\text { sigma virus [73]. Upregulated in young } \\
\text { fly guts [72]. }\end{array}$ \\
\hline FBti0019386 & $\begin{array}{l}\text { invader4 } \\
\text { (LTR) }\end{array}$ & $\begin{array}{l}3 R: \\
16189464\end{array}$ & $\begin{array}{l}347 \mathrm{bp} \\
\text { (T: solo } \\
\text { LTR) }\end{array}$ & $\begin{array}{l}\text { CL test, } \\
\text { TajimaD, } \\
\text { Phenotypic } \\
{[74]}\end{array}$ & $\begin{array}{l}\text { Bin1 (5' } \\
\text { UTR) }\end{array}$ & $\begin{array}{l}\text { Survival. Mutant larvae are more } \\
\text { sensitive to fungal A. fumigatus (fungi) } \\
\text { infection [75]. }\end{array}$ \\
\hline FBti0019985 & roo (LTR) & $\begin{array}{l}2 R: \\
9871090\end{array}$ & $\begin{array}{l}434 \text { bp } \\
\text { (T: solo } \\
\text { LTR) }\end{array}$ & $\begin{array}{l}\text { TajimaD, } \\
\text { iHS, H12, } \\
\text { Phenotypic } \\
{[76]}\end{array}$ & $\begin{array}{l}c b x \text { (first } \\
\text { intron) }\end{array}$ & $\begin{array}{l}\text { Survival. Mutant flies are more sensitive } \\
\text { to S. aureus (gram-positive) septic } \\
\text { infection, but not to S. typhimurium } \\
\text { (gram-negative) infection [77]. }\end{array}$ \\
\hline FBti0019564 & $\begin{array}{l}\text { mdg1 } \\
\text { (LTR) }\end{array}$ & $\begin{array}{l}\text { X: } \\
3785867\end{array}$ & $\begin{array}{l}189 \mathrm{bp} \\
(\mathrm{T}: \\
\text { LTR) }\end{array}$ & TajimaD [78] & tlk (intron) & $\begin{array}{l}\text { Survival. Involved in antimicrobial } \\
\text { humoral response to gram-negative } \\
\text { [57]. tlk knockdown, together with other } \\
\text { five genes knocked-down, reduces } \\
\text { phagocytosis of E. coli (gram-negative) } \\
\text { and S. aureus (gram-positive) in S2 cells } \\
\text { [79]. }\end{array}$ \\
\hline FBti0020119 & $S(D N A)$ & $\begin{array}{l}3 \mathrm{~L}: \\
15554974\end{array}$ & $\begin{array}{l}1732 \\
b p(F L)\end{array}$ & NS & $\begin{array}{l}\mathrm{AGO2} \\
\text { (first } \\
\text { intron) }\end{array}$ & $\begin{array}{l}\text { Survival. Involved in defense response } \\
\text { to virus infections [80, } 81] \text {, and interacts } \\
\text { with Imd pathway proteins during } \\
\text { gram-negative infection [82]. }\end{array}$ \\
\hline FBti0020137 & $S(D N A)$ & $\begin{array}{l}3 \mathrm{~L}: \\
17799864\end{array}$ & $\begin{array}{l}1732 \\
\mathrm{bp}(\mathrm{FL})\end{array}$ & NS & $\begin{array}{l}\text { NUCB1 } \\
\text { (first } \\
\text { intron) }\end{array}$ & $\begin{array}{l}\text { Survival. Mutants are more resistant to } \\
\text { V. cholerae (gram-negative) oral } \\
\text { infection [83]. }\end{array}$ \\
\hline FBtio061506 & $\begin{array}{l}1360 \\
\text { (DNA) }\end{array}$ & $\begin{array}{l}2 \mathrm{~L}: \\
17432071\end{array}$ & $\begin{array}{l}48 \mathrm{bp} \\
(\mathrm{T}: \mathrm{TIR})\end{array}$ & iHS [52] & $\begin{array}{l}\text { Dif (first } \\
\text { intron) }\end{array}$ & $\begin{array}{l}\text { Survival and expression. Transcription } \\
\text { factor involved in defense response to } \\
\text { fungus and gram-positive bacteria and } \\
\text { mediates Toll pathway activation [84- } \\
\text { 88]. Dif mutants are susceptible to fungi } \\
\text { and gram-positive bacterial infection } \\
\text { [88, 89]. Upregulated in guts from } P \text {. } \\
\text { entomophila infected flies [41]. }\end{array}$ \\
\hline FBti0018877 & $\begin{array}{l}\text { BS (non- } \\
\text { LTR) }\end{array}$ & $\begin{array}{l}\text { 2R: } \\
9945496\end{array}$ & $\begin{array}{l}131 \mathrm{bp} \\
\left(\mathrm{T}: 5^{\prime}\right)\end{array}$ & NS & $\begin{array}{l}\text { Mef2 (first } \\
\text { intron) }\end{array}$ & $\begin{array}{l}\text { Survival and expression. Adult Mef2 } \\
\text { mutant males are more sensitive to } E \text {. } \\
\text { cloacae (gram-negative) and } M \text {. } \\
\text { marinum (gram-positive) septic infection } \\
\text { [90]. Upregulated after } 4 \mathrm{~h} \text { of infection } \\
\text { with P. entomophila (gram-negative) } \\
\text { [41]. }\end{array}$ \\
\hline \multirow[t]{2}{*}{ FBti0018868 } & 297 (LTR) & $\begin{array}{l}2 R: \\
23877783\end{array}$ & $\begin{array}{l}414 \text { bp } \\
(T: \\
\text { LTR) }\end{array}$ & NS & $\begin{array}{l}\text { TM4SF (1 } \\
\text { bp 5') }\end{array}$ & $\begin{array}{l}\text { A tetraspanin transmembrane protein, } \\
\text { which modulate immune-signaling in } \\
\text { Drosophila [53]. }\end{array}$ \\
\hline & & & & & $\begin{array}{l}\text { ken }(340 \\
\left.\text { bp } 3^{\prime}\right)\end{array}$ & $\begin{array}{l}\text { JAK-STAT. Member of JAK-STAT path- } \\
\text { way [91]. JAK-STAT pathway plays a role } \\
\text { in immune response in D. melanogaster } \\
\text { [54]. }\end{array}$ \\
\hline
\end{tabular}




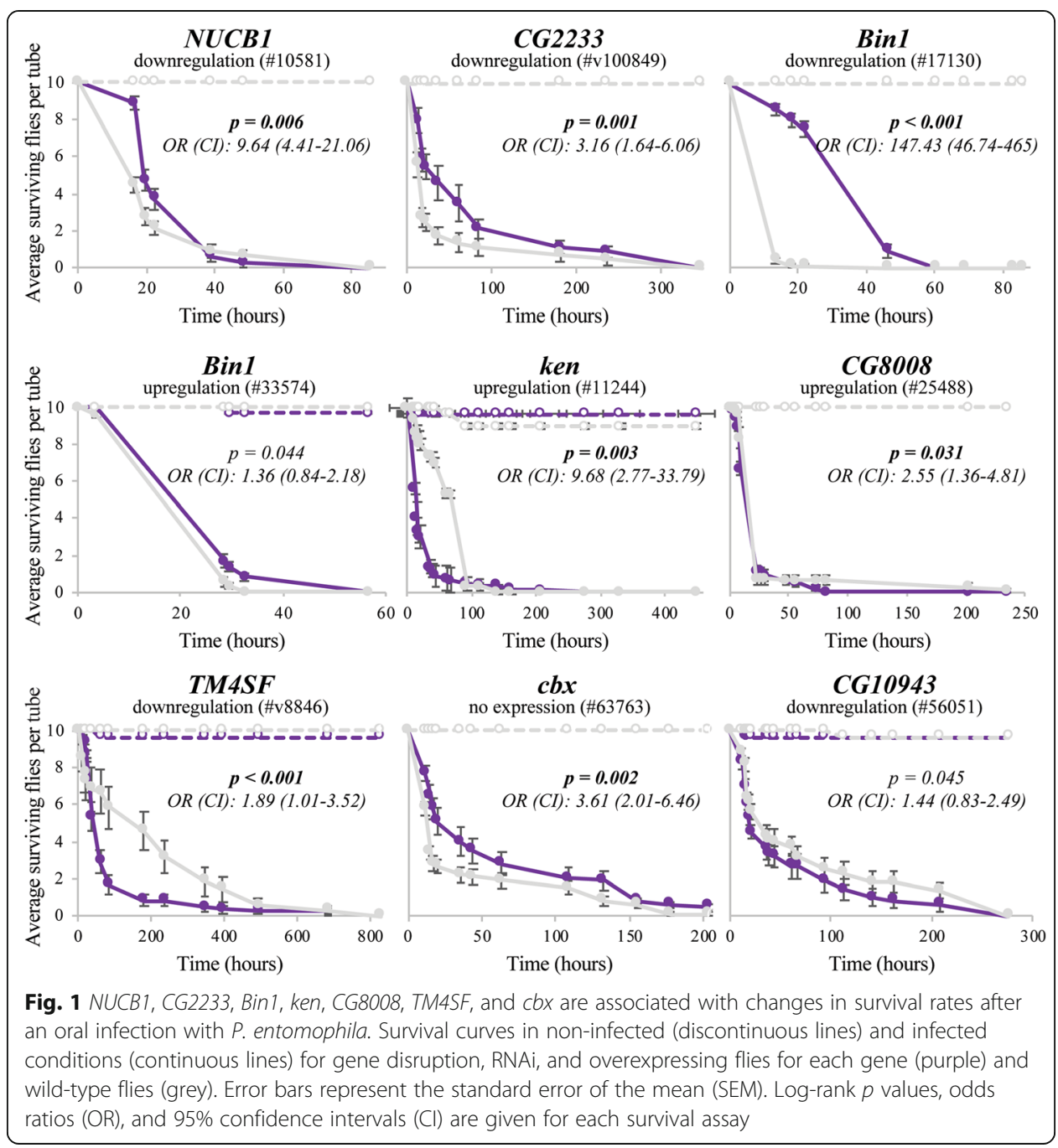

changes in NUCB1, CG2233, Bin1, and $c b x$ were associated with higher survival, while expression changes in ken, CG8008, and TM4SF were associated with lower survival (Fig. 1, Additional file 2C). For CG10943 and for one of the two backgrounds tested for Bin1-although we found differences in survival - the effect size was not significant (Fig. 1, Additional file 2C).

Overall, we identified 19 candidate adaptive TEs located near 21 immune-related genes. While for some of these genes there is previous evidence linking changes in expression with changes in survival to infection (Table 1), we provided additional evidence for seven genes further suggesting that they do play a role in immune response (Fig. 1, Additional file $2 \mathrm{~B}$ and $2 \mathrm{C}$ ). Note that there is prior evidence suggesting that seven of these 19 TEs have increased in frequency due to positive selection (Table 1) [52]. We next investigated whether the identified candidate adaptive TEs were associated with changes of expression of their nearby immunerelated genes. 
Immune-related candidate TEs are associated with gene expression changes

In order to explore whether the 19 candidate adaptive TEs were associated with expression changes of their nearby immune-related genes, we measured allele-specific expression (ASE) in flies heterozygous for the presence of each candidate adaptive TE. Because both alleles in the heterozygote share the same cellular environment, differential expression of the two alleles is indicative of functional cis-regulatory differences $[92,93]$. We performed the analysis in flies with two different genetic backgrounds in order to detect possible background-dependent effects in allele-specific expression changes.

We were able to analyze a total of 16 genes located nearby 14 TEs (see the "Methods" section). In non-infected conditions, 10 out of the 16 genes showed statistically significant allele-specific expression differences in at least one of the two genetic backgrounds analyzed (Fig. 2, Additional file 3). For five of these genes, we found that the allele with the TE was more highly expressed compared with the allele without the TE, and for the other five genes, the allele with the TE was less expressed. In infected conditions, eight out of the 16 genes showed statistically significant allele-specific expression differences in at least one of the two genetic backgrounds analyzed (Fig. 2, Additional file 3). For three of these genes, we found that the allele with the TE was more highly expressed, and for the other five genes, the allele with the TE was less expressed. Note that upregulation of CG10943 and Dif, and downregulation of CG8628, CG15096, NUCB1, and $c b x$ in infected conditions have been previously associated with increased tolerance to infection (Table 1) $[41,77,83]$.

Considering both non-infected and infected conditions, five genes showed allelespecific expression differences under both conditions: for CG10943, the allele with the TE was more highly expressed, and for CG8628, CG8008, CG15096, and $c b x$, the allele with the TE was less expressed (Fig. 2, Additional file 3).

We also checked whether the genetic background affected the allele-specific expression differences. In ten of these comparisons, both backgrounds showed changes in expression in the same direction, and in two of them, the differences were statistically significant in the two backgrounds analyzed (Fig. 2, Additional file 3). On the other hand, while seven analyses showed differential expression in opposite directions in the two backgrounds, results were always only statistically significant in one of the two backgrounds analyzed (Fig. 2, Additional file 3).

Finally, we checked whether there were polymorphisms linked to the presence of the TE insertion that could also be associated with the detected differences in allele expression (see the "Methods" section). Only for the AGO2 gene, we found two single nucleotide polymorphisms (SNPs) in the coding region that were linked to FBti0020119 insertion (Additional file 6B). Thus, and although we cannot completely exclude that other polymorphisms could also be playing a role, the TE insertion appeared to be the most likely causal mutation with the exception of FBti0020119.

Overall, we found that most of the candidate immune-related TEs, 12 out of 14, were associated with changes in expression of their nearby gene, in at least one of the two conditions analyzed (Fig. 2). While some expression changes are significant only in infected or only in non-infected conditions, a significant proportion of 


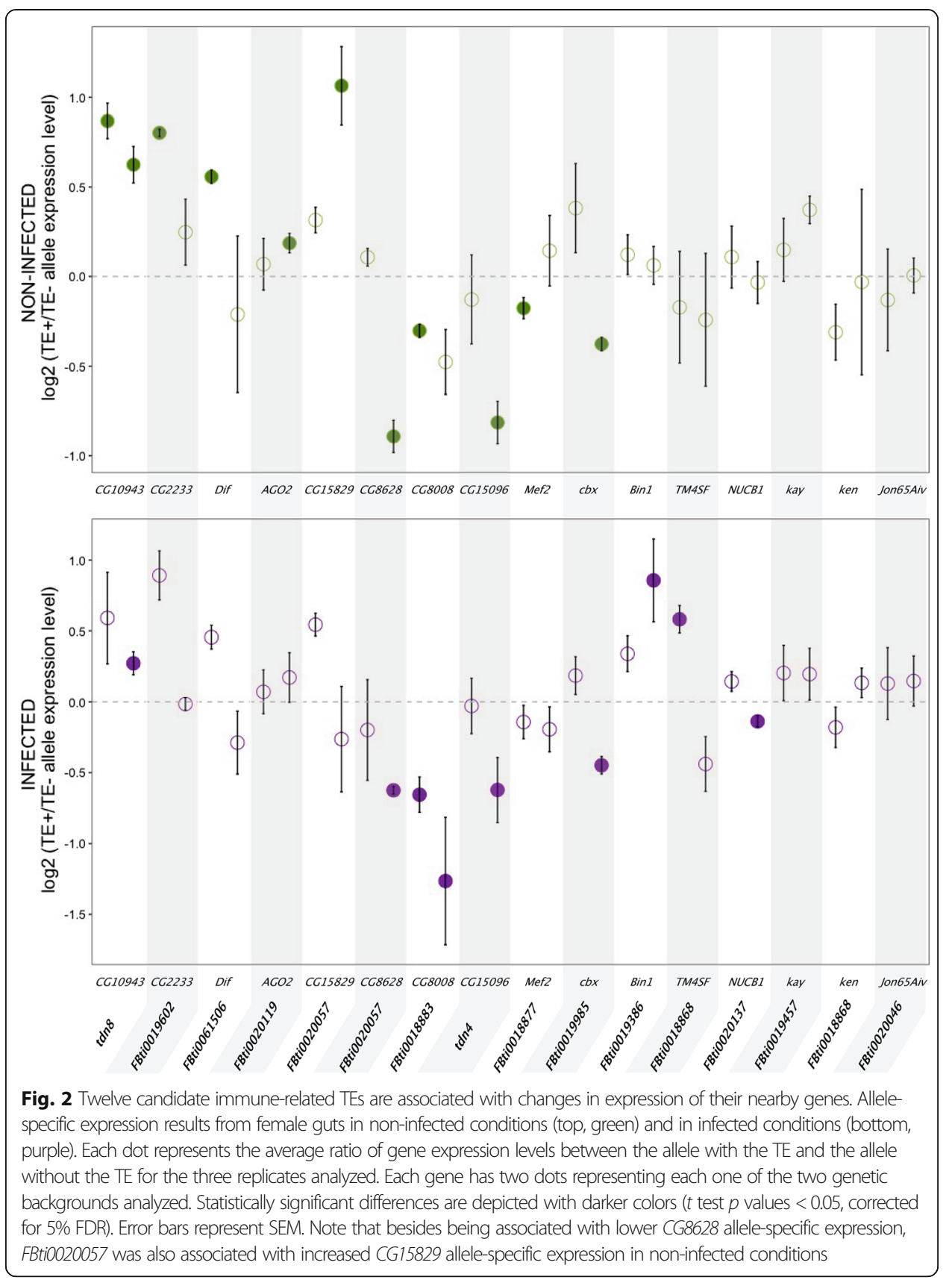

genes (38\%) showed consistent changes in expression in both conditions (Fig. 2). We also detected an effect of the genetic background on the allele-specific expression differences as has been previously reported [94-96]. Finally, while recent studies performed in several $D$. melanogaster strains estimated that $\sim 8$ to $28 \%$ of genes showed allele-specific expression in control conditions [69, 97, 98], we found this percentage to be $62.5 \%$, which is significantly higher than the previous reported higher value (Fisher test: $p$ value $=0.0087$ ) 
Candidate adaptive TEs associated with lower allele-specific expression are not enriched for the repressive histone mark $\mathrm{H} 3 \mathrm{~K} 9 \mathrm{me} 3$

Six of the TEs analyzed were associated with lower allele-specific expression levels (FBti0020057, FBti0018883, tdn4, FBti0018877, FBti0019985, and FBti0020137; Fig. 2). One of the molecular mechanisms by which TEs are associated with gene downregulation is by recruiting repressive histone marks such as H3K9me3 [99-101]. Thus, we checked whether flies homozygous for each one of these insertions showed H3K9me3 enrichment in the region where the TE is inserted compared with strains without the insertions. We found that the strains with the insertion were not enriched in H3K9me3 histone mark compared with the strains without the insertion ( $p$ values $>0.05$ ) (Fig. 3A). Indeed, for FBti0019985, we found a depletion of H3K9me3 in the TE region (Fig. 3A). Thus, the lower allele-specific expression associated with the TEs observed in the ASE analysis is not due to changes in H3K9me3 repressive histone mark (Fig. 3A).

An alternative hypothesis is that these TE insertions could be recruiting transcriptional repressors or that they are disrupting regulatory regions. To provide evidence that these TE insertions could indeed be the mutations associated with the lower allele-specific expression levels, for one of them (FBti0020057), we cloned the gene promoter region with and without the TE insertion in front of a reporter gene. We indeed found that flies with FBti0020057 insertion were associated with lower reporter gene expression both in control and infected conditions (Fig. 3B; $t$ test, $p$ value $=0.019$ and 0.016 , respectively). Although we cannot discard that FBti0020057 is associated with gene downregulation because it disrupts the promoter gene region, it has been reported that this insertion contains a binding site for $N u b$, a transcription factor which negatively regulated many genes involved in immune and stress responses (Additional file 1E) [102].

\section{Two of the four tested candidate adaptive TEs associated with high allele-specific} expression drives reporter gene expression under stress conditions

There is previous evidence showing that FBti0019386, which is associated with increased allele-specific expression in infected conditions, drives the expression of a reporter gene after oral infection with P. entomophila [25]. To test whether other TEs associated with increased expression of their nearby genes could also be acting as enhancers, we performed in vivo enhancer assays. We focused on three insertions located in promoter regions (less than $1 \mathrm{~kb}$ from a gene) and associated with $\geq 1.5$-fold increased expression: $t d n 8$, FBti0018868, and FBti0061506.

We found that transgenic flies in which we cloned the upstream gene region containing the $t d n 8$ sequence showed increased reporter gene expression compared with transgenic flies containing the same region without the insertion (Fig. 4A). Differences in gene expression were only statistically significant in infected conditions $(t$ test, $p$ value $=0.095$ and 0.046 for control and infected conditions, respectively; effect size 1.4 and 1.5 for control and infected conditions, respectively). No differences between the two transgenic strains in the localization of the $\beta$-GAL protein expression in control or infected conditions were found (Fig. 4A). On the other hand, we found that neither FBti0018868 nor FBti0061506 drive the expression of a reporter gene in non-infected or infected conditions (Fig. $4 \mathrm{~B}$ and $\mathrm{C}$; $t$ test, all $p$ values $>0.05$ ). 

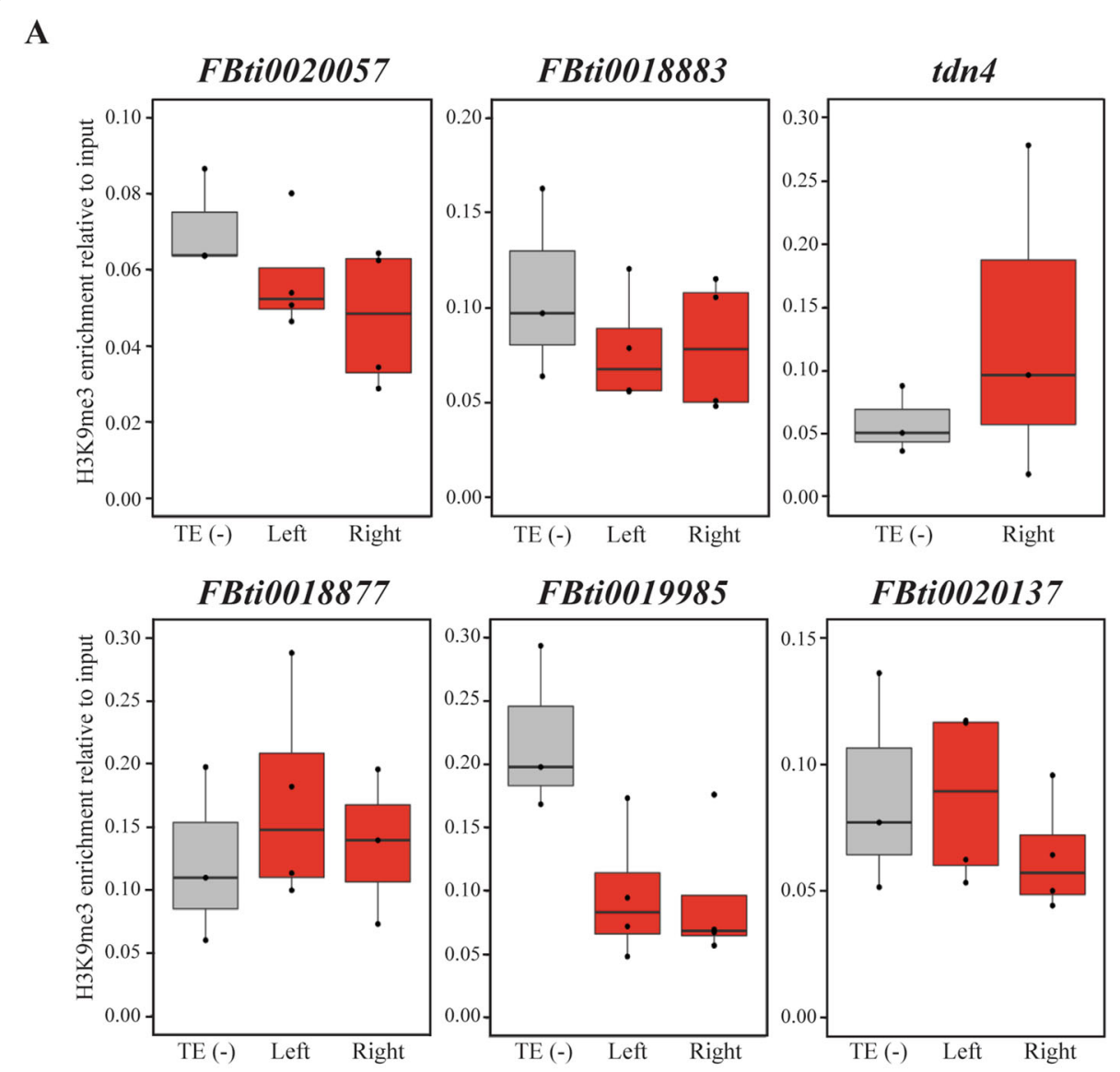

B
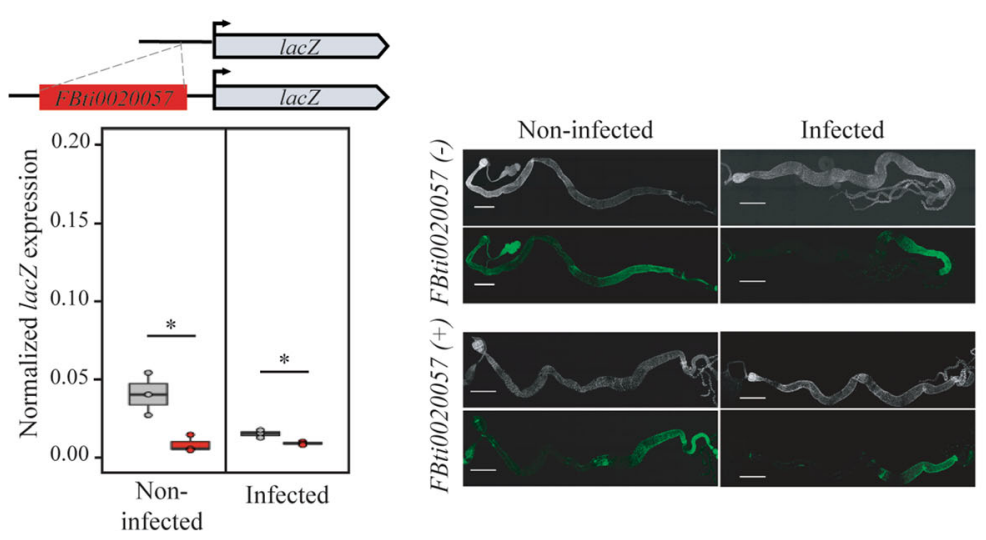

Fig. 3 (See legend on next page.) 
(See figure on previous page.)

Fig. 3 Candidate immune-related TEs associated with lower allele-specific expression are not enriched for H3K9me3. A ChIP qPCR analysis for H3K9me3 in the genomic region where FBti0020057, FBti0018883, tdn4, FBti0018877, FBti0019985, and FBti0020137 are inserted. TE (-): H3K9me3 enrichment in the strain that does not contain the TE insertion (grey). Left: H3K9me3 enrichment in the left flanking region of each TE in a strain with the insertion (red). Right: $\mathrm{H} 3 \mathrm{~K} 9 \mathrm{me} 3$ enrichment in the right flanking region of each TE in a strain with the insertion (red). None of the candidate immune-related TEs tested are enriched for H3K9me3. FBti0020057: $p=0.384$ and $p=0.115$ for the left and right TE-flanking regions, respectively; FBti0018883: $p=$ 0.473 and $p=0.425$, respectively; $t d n 4: p=0.408$ for the right TE-flanking region; FBti0018877: $p=0.364$ and $p=0.632$, respectively; FBti0019985: $p=0.041$ and $p=0.039$, respectively; and FBti0020137: $p=0.880$, and $p$ $=0.423$, respectively. B FBti0020057 is associated with lower reporter gene expression in both non-infected and infected conditions. Schematic representation of the vector construction with the intergenic region between CG15829 and CG8628 genes with and without FBti0020057 insertion cloned upstream of the reporter gene lacZ. Below, normalized expression levels of the lac $Z$ reporter gene in transgenic female guts with (red) and without (grey) FBti0020057 are shown. On the right side, $\beta-G A L$ immunostaining (green), and DAPI staining (grey) of guts from transgenic females with and without FBti0020057. Scale bars represent $500 \mu \mathrm{m}$

Overall, we found that two of the four tested TE insertions that are associated with $\geq$ 1.5-fold higher allele-specific expression drive the expression of a reporter gene (Fig. 4). For the rest of this work, we focus on the FBti0019386 insertion as a case study to further understand the molecular mechanisms and the phenotypic consequences of a candidate insertion related to immune response.

\section{FBti0019386 adds immune-related transcription factor binding sites}

Villanueva-Cañas et al. (2019) [25] reported that FBti0019386, which drives the expression of a reporter gene only in infected conditions, harbors two immune-related binding sites for Caudal and DEAF-1 transcription factors (Additional file 1E) [103-105]. To test whether the predicted immune-related transcription factor binding sites (TFBSs) were responsible for the enhancer activity of this insertion in infected conditions, we generated a transgenic fly line in which we deleted the two binding sites from the FBti0019386 insertion sequence (Fig. 5A). We performed expression analysis with the two previously generated transgenic lines described in Villanueva-Cañas et al. (2019) [25], one containing the Bin1 upstream region without the insertion, and one containing the $\operatorname{Bin} 1$ upstream region with the insertion, and with the newly generated transgenic line in which the FBti0019386 TFBSs were deleted.

As expected based on previous experiments, we found that guts from transgenic flies containing the TE insertion showed increased reporter gene expression compared with transgenic flies without the insertion in infected conditions (Fig. 5A; $t$ test, $p$ value < 0.001) [25]. Moreover, as expected if the binding sites for Caudal and DEAF-1 are responsible for the increase expression of the reporter gene, the transgenic flies in which these binding sites were deleted showed decreased reporter gene expression in infected conditions (Fig. 5A; $t$ test, $p$ value $=0.009$ ).

\section{FBti0019386 provides a transcription start site to Bin 1 that is only used in infected} conditions in the female gut

There is also evidence showing that FBti0019386 adds a transcription start site to its nearby gene Bin1 (Fig. 5B) [24, 106]. We thus further investigated the expression levels of Bin1 transcripts in strains with and without FBtiO019386 insertion, in control and in 
A. $\operatorname{tdn} 8$
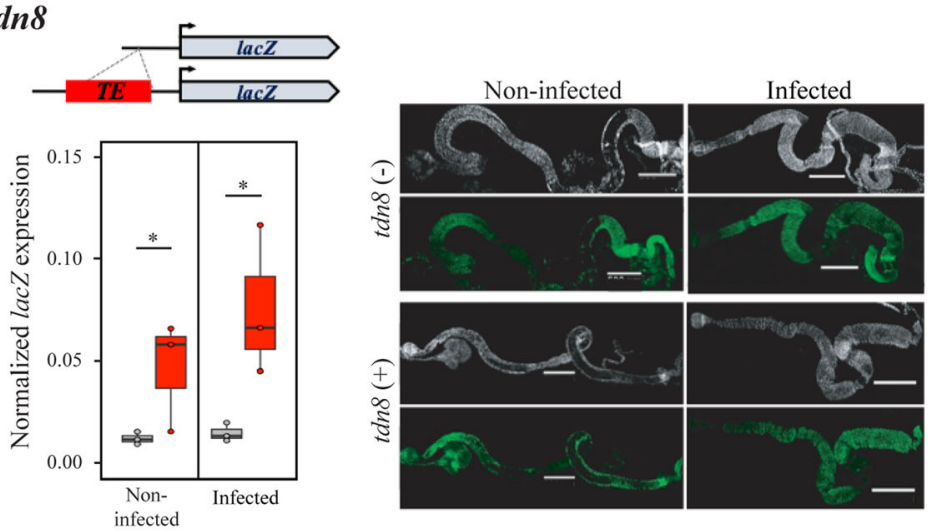

\section{B. FBti0018868}
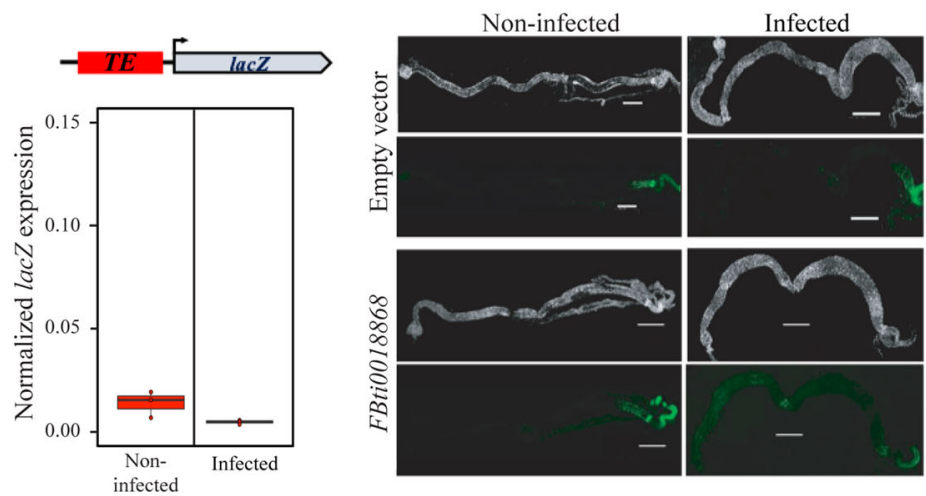

C. FBti0061506
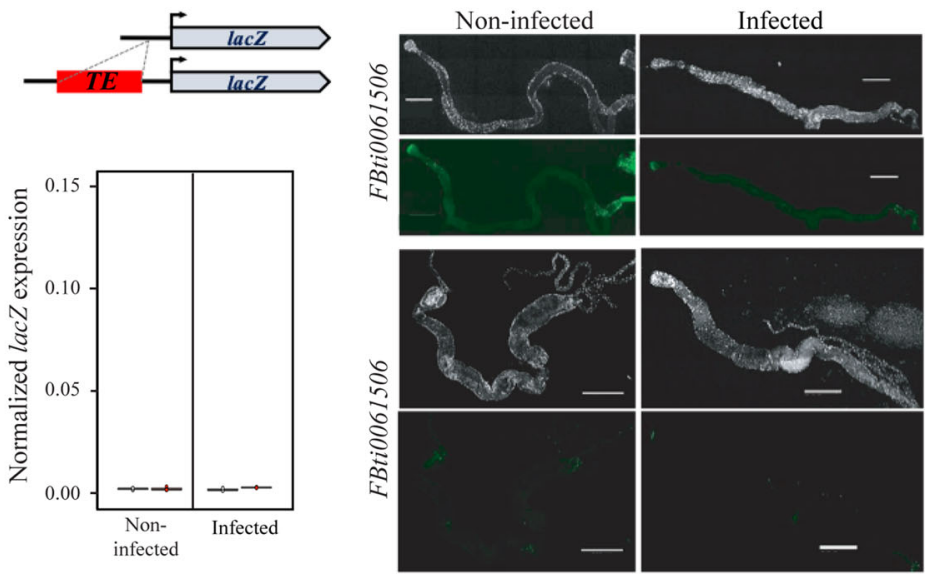

Fig. $4 t d n 8$ insertion showed increased reporter gene expression. Results of the in vivo enhancer reporter assays for A tdn8, B FBti0018868, and C FBti0061506. Normalized expression levels of the lacZ reporter gene in transgenic female guts with (red) and without (grey) the candidate TE insertions are shown. $\beta$-GAL immunostaining (green), and DAPI staining (grey) of guts from transgenic females with and without each candidate TE insertions is also shown. Scale bars represent $500 \mu \mathrm{m}$

infected conditions. We found that female guts from homozygous flies with and without FBti0019386 expressed only the short Bin1-RA transcript in non-infected conditions (Fig. 5B). However, in infected conditions, flies without FBti0019386 insertion only expressed Bin1-RA, while flies with FBti0019386 expressed Bin1-RA, and three additional transcripts starting in the TE: Bin1-RC, Bin1-RD and Bin1-RE (Fig. 5B). We 


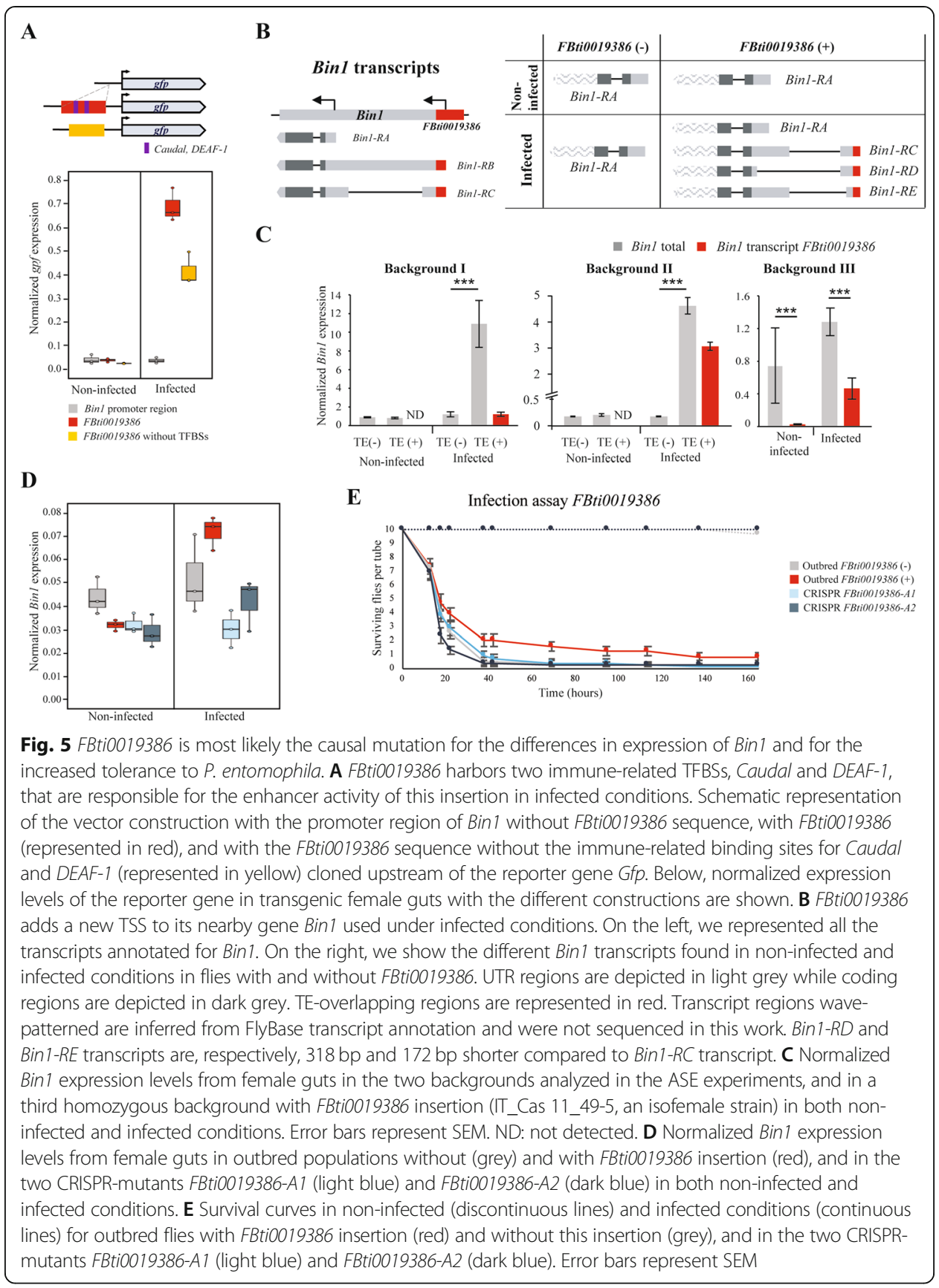

confirmed these results by performing the experiments in a second genetic background (see the "Methods" section). Note that the Bin1-RD and Bin1-RE transcripts have not been described previously and differ in the 5'UTR length (Fig. 5B).

To test whether the transcripts starting in FBti0019386 insertion are associated with increased expression of Bin1, we quantified the expression of these transcripts and the total Bin1 expression levels (Fig. 5C). As expected based on our previous ASE experiments, flies with and without FBti0019386 did not differ in Bin1 expression levels in non-infected conditions ( $t$ test, $p$ value $>0.05$ ). In infected conditions, flies with FBti0019386 overexpressed Bin1 compared to flies without this insertion in the two backgrounds analyzed ( $t$ test, $p$ value $<0.001)$. The contribution of the transcripts 
starting in FBti0019386 to the total Bin1 expression is background dependent: $11.2 \%$ in background I, and $66.3 \%$ in background II (Fig. 5C). To confirm that the effect is background-specific, we analyzed a third background, and we found that the TEtranscripts contributed $36.2 \%$ to Bin1 total expression (Fig. 5C). These results suggest that besides adding a transcription start site, FBti0019386 is also affecting the expression level of the short transcript, which is consistent with the enhancer role described for this TE (Fig. 5A) [25].

FBti0019386 appears to be the causal mutation for the differences in expression of its nearby gene

To further test that FBti0019386 is indeed the mutation causing the observed differences in expression, we generated two outbred populations, one containing the FBti0019386 insertion and one without this insertion. We then deleted the insertion using the CRISPR/ Cas9 homology directed repair technology and established two stocks containing this deletion (FBti0019386-A1 and FBti0019386-A2; see the "Methods" section). We tested the expression of Bin1 in the two outbred and the two CRISPR/Cas9 mutant strains. We found that outbred flies with the insertion had increased Bin1 expression levels compared with outbred flies without the insertion in infected conditions (two-way ANOVA; genotype effect: $p=0.501$, treatment effect: $p=0.003$, interaction genotype"treatment: $p=$ 0.025) (Fig. 5D). These results are consistent with the TE acting as an enhancer only in infected conditions (Fig. 5A). We also found reduced Bin1 expression levels in the two CRISPR/Cas9 mutant strains only in infected conditions, consistent with FBti0019386 being the causal mutation (FBti0019386-A1: two-way ANOVA; genotype effect: $p<0.001$, treatment effect: $p<0.001$, interaction genotype treatment: $p<0.001$, and FBti0019386$A 2$ : two-way ANOVA; genotype effect: $p=0.006$, treatment effect: $p<0.001$, interaction genotype"treatment: $p=0.016$ ) (Fig. 5D).

In summary, while outbred populations with FBti0019386 insertion showed increased Bin1 expression levels, this expression was significantly reduced when the FBti0019386 was deleted from its genomic context (Fig. 5D).

\section{FBti0019386 is associated with increased tolerance to $P$. entomophila infection}

To check whether the changes in Bin1 expression most likely caused by FBti0019386 have an effect on the fly immune response, we measured the tolerance to oral infection of P. entomophila in both outbred and CRISPR/Cas9 mutant strains. We found that outbred flies with FBti0019386 showed increased tolerance to infection compared to outbred flies without the insertion (log rank; $p$ value $=0.049)($ Fig. 5E). Although both CRISPR/Cas9 mutants have reduced tolerance compared to the strain with the TE, only FBti0019386-A2 flies showed statistically significant differences in survival (log rank; $p$ value $=0.060$ and $p$ value $=0.001$, respectively) (Fig. $5 \mathrm{E}$ ).

Overall, we showed that FBti0019386 is most likely the causal mutation for the increased tolerance to bacterial infection found in natural populations containing this TE insertion.

\section{Discussion}

In this work, we identify 12 transposable element (TE) insertions associated with allelespecific expression differences in immune-related genes (Figs. 2 and 6). Allele-specific 


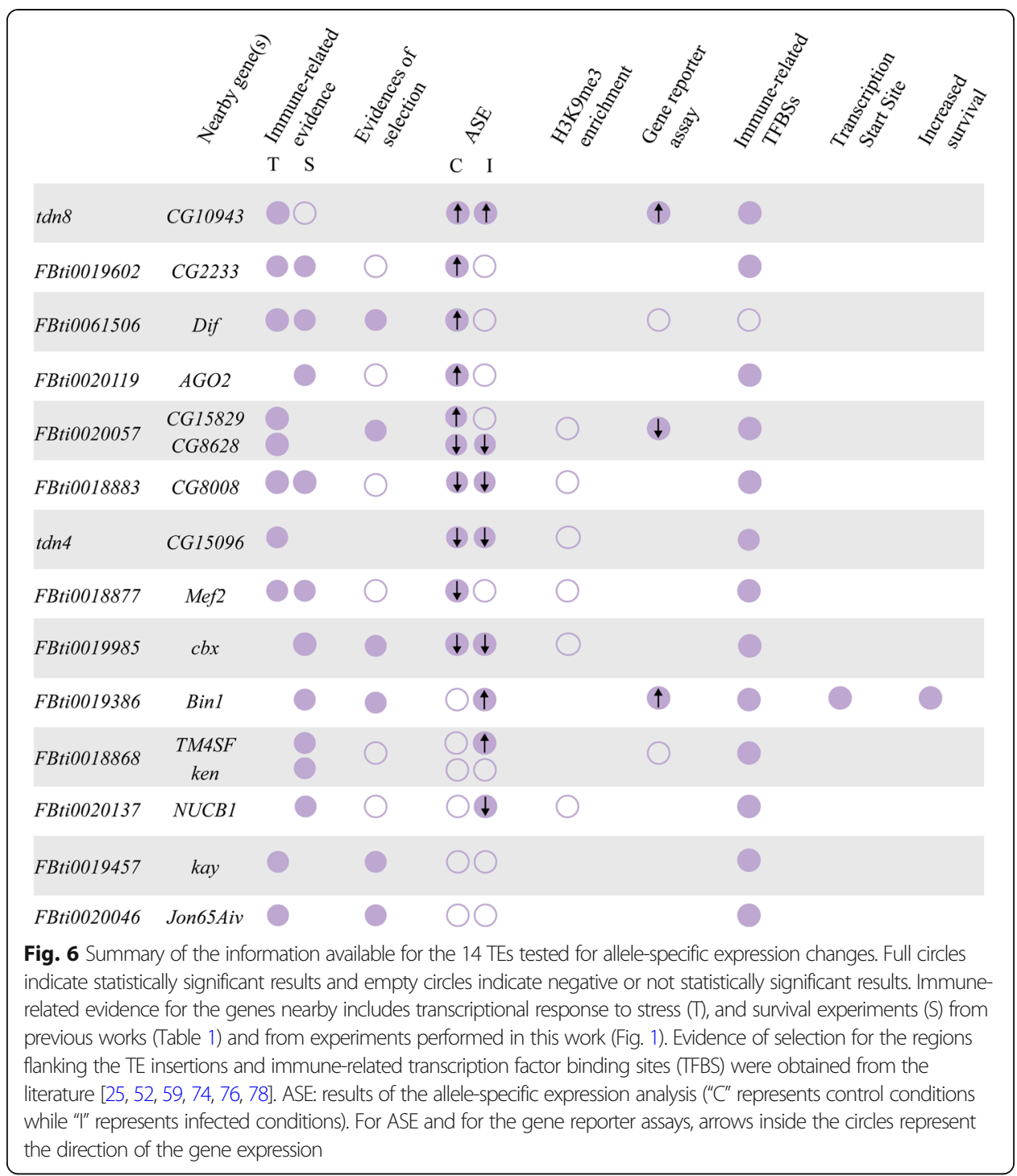

expression analysis is a powerful technique to identify cis-regulatory variants [92, 93]. Because the two alleles studied shared the same cellular environment, differences in expression found between them are indicative of functional cis-regulatory differences. Several works have tried to quantify the relative contribution of cis-regulatory mutations to gene expression changes in $D$. melanogaster $[69,97,98]$. While these studies found that between $\sim 8 \%$ and $28 \%$ of $D$. melanogaster genes showed allele-specific expression, we found a significantly higher proportion $(62.5 \%$, Fisher test: $p$ value $=$ 0.0087). While these results might be at least partly explained by immune-related genes having an elevated rate of adaptive evolution, a global survey in Drosophila suggested that rapid adaptation of immune-related genes is the exception rather than the rule $[107,108]$.

There is prior evidence showing that the presence of TE insertions within $1 \mathrm{~kb}$ of a gene is associated with a larger contribution to cis-regulatory expression variation compared with genes that do not have TE insertions in their vicinity [97]. However, this observation was found to be limited to genes expressed in the ovary. Our results indicate 
that TEs contribute to allele-specific expression in immune-related genes expressed in the gut. It would be interesting to test whether TEs are associated with an increased contribution to cis-regulatory changes in genes involved in other functions as well, as suggested by the enrichment of TEs nearby or inside genes involved in stress-response, behavior, and development [52]. While we focused on P. entomophila as an infectious agent in female flies, it would also be interesting to use other pathogens to check whether the observed effects are pathogen-specific. Similarly, male flies may be used to know whether the effect of the candidate TEs varies between sexes, as it is known that sexual dimorphisms have an impact on pathogen-host interactions [109].

We found that some TEs were associated with gene downregulation while others were associated with gene upregulation (Fig. 2). While rare TE insertions have previously been associated with reductions in gene expression [110], no significant differences in the direction of the effect in expression were found for TEs located nearby genes in another study also performed in D. melanogaster, and in a study conducted in humans $[19,97]$. To provide further evidence for the regulatory role of the candidate TEs, we attempted to pinpoint the molecular mechanisms behind these expression changes. TE-induced gene silencing has been associated with epigenetic changes [99, 100, 111]. Specifically, enrichment of the repressive chromatin mark H3K9me3 in the sequences flanking euchromatic TEs was associated with reduced expression of adjacent genes [99, 112]. Contrary to our expectation, we did not find an enrichment of H3K9me3 in the regions flanking the six TE insertions analyzed (Figs. 3 and 6). Interestingly, recent genome-wide analyses of silencer elements also failed to identify particular histone modifications associated with these regulatory sequences $[4,5,113]$. Jayavelu et al. (2020) found that on average only 3.3\% of silencer elements overlap with H3K9me3 regions [5]. Thus, the lack of histone marks does not necessarily preclude the role of these TE insertions in gene silencing. Indeed, we found that one of these insertions was associated with the downregulation of a reporter gene (Fig. 3B). In vivo enhancer assays also confirmed that two of the four insertions associated with gene upregulation act as enhancers (Figs. 4 and 6) [25]. Because enhancer reporter assays select for compact regulatory elements that can function in an autonomous manner, we cannot discard the causal role of the insertions that failed to drive reporter gene expression [114]. Moreover, because enhancer assays could also lead to false positive results, they should be combined with assays in the native genomic context of the regulatory element such as for example creating a CRISPR/Cas9 mediated genomic deletion of the region under study [115]. We did so for one of the TEs found to be acting as an enhancer, FBti0019386, and we were able to confirm that the TE is indeed responsible for the increased expression of its nearby gene (Fig. 5). Furthermore, we showed that the increased expression is due to the presence of binding sites for immune-related transcription factors and to the expression of a transcript that starts in the TE insertion (Fig. 5). This result is consistent with the dual role of regulatory regions as enhancers and promoters as has been previously suggested $[2,116]$. Note that the overall success validation rate in our in vivo gene reporter assays is similar to that of other studies not focused on TE insertions (60\%) [117, 118].

Finally, we also investigated whether the TE-induced changes in these genes could be relevant for the fly ability to cope with infections. Both gene upregulation and downregulation have been previously related to $D$. melanogaster gut immune response [38, 46]. 
Similarly, changes in basal gene expression, as we found in this work, also affect the susceptibility of the flies to immune-challenges $[41,119]$. If we focus on particular genes, upregulation of CG10943 and Dif, and downregulation of CG8628, CG15096, $N U C B 1$, and $c b x$ in infected conditions has been associated with increased tolerance to infection [41, 77, 83]. Because we found that $t d n 8$, FBti0061506, FBti0020057, tdn4, FBti0020137, and FBti0019985 induced expression changes in these genes in the same direction, we argue that it is likely that these TEs will also be associated with increased tolerance to infection (Fig. 2). For another TE, FBti0019386, we performed survival experiments with natural populations and with CRISPR/Cas9 mutant strains in which the TE was deleted, and we found that this insertion is associated with increased survival (Fig. 5).

\section{Conclusions}

We showed that TEs contribute to gene expression variation during infection in $D$. melanogaster and that this variation is likely to affect the fly infection survival capacity. Because the role of TEs as regulatory elements is not restricted to Drosophila, TEs are likely to be key players in immune response in other organisms as well [14, 120]. For example, in humans, over $80 \%$ of genetic variants associated with infection risk map to the non-coding genome [121]. Among the structural variants likely to play a role, TE insertions are good candidates as they have been found to be associated with expression changes in immune-related genes in human populations [122].

\section{Methods}

\section{Fly strains}

DGRP strains

One hundred forty-one DGRP strains [123] were used to estimate the frequencies of TEs annotated in the D. melanogaster reference genome (see below) (Additional file 4). Besides, we used 37 DGRP strains to analyze by PCR a subset of TEs not annotated in the reference genome (51). Finally, DGRP strains were also used to perform allele- specific expression analyses (ASE), detection of alternative transcripts, and enhancer assays (Additional file 4). Note that it has previously been shown that differences in the presence/absence of the endosymbiont Wolbachia, differences in commensal bacteria and/ or feeding behavior has no major effect in the susceptibility of DGRP strains to P. entomophila infection [41].

\section{African strains}

Frequency estimates for reference TE insertions for a subset of 66 African strains collected in Siavonga (Zambia) [124] with no evidence of cosmopolitan admixture were obtained from Rech et al. (2019) [52] (Additional file 4).

\section{European strains}

Frequency estimates for reference TE insertions for 73 European strains, 57 from Stockholm (Sweden) and 16 from Bari (Italy), were obtained from Rech et al. (2019) [52] (Additional file 4). Additionally, one strain from Bari (IT_Cas 11_49-5) was used 
for ASE and detection of alternative transcripts experiments and one strain from Munich (DE_Mun_15_8) was used for ASE experiments (Additional file 4).

\section{Gene disruption, RNAi knockdown, and overexpression strains}

We used two RNAi strains from the VDRC stock center (Additional file 2A). To generate the mutants, we crossed the strains carrying the RNAi controlled by an UAS promoter with flies carrying a GAL4 driver (a transcription activation system) to silence genes ubiquitously. We performed the experiments with F1 flies that were obtained from each cross. Based on the phenotypic markers, we separated the RNAi flies from the rest of the F1 that do not carry the GAL4 driver. The flies without the GAL4 driver were used as the baseline of the experiment. We also used nine mutant strains generated with different transposable element insertions and two overexpression strains. In this case, we used strains with similar genetic backgrounds as the baseline of the experiments (Additional file 2A).

\section{Outbred strains}

We generated present and absent outbred strains for FBti0019386. First, we selected all the strains that were present or absent for this TEs based on data generated by T-lex2 in the DGRP, Zambia, Sweden, and Italy populations [52]. Then, in these selected strains, we checked by PCR the presence/absence of other eleven TEs identified is this work as they are likely to be involved in the immune response (FBti0019985, FBti0061506, FBti0019602, FBti0020119, FBti0018883, FBti0018877, FBti0020137, FBti0020057, FBti0018868, $t d n 4$, and $t d n 8$ ). For generating both TE-present and TEabsent outbred populations, we selected six strains with the insertion and six strains without the insertion, respectively (Additional file 4). Moreover, present and absent outbred populations have similar frequencies of all the other eleven TEs likely to be involved in immune responses in order to not mask the effect of the studied TE. For every outbred population, we placed 10 males and 10 virgin females of each selected strain in a cage with fresh food. We maintained the population by random mating with a large population size for over four generations before starting the experiments.

\section{CRISPR/Cas9 mutant strains}

Guide RNAs (gRNAs) were designed in the FBti0019386 flanking region using the Fly CRISPR Target Finder (http://targetfinder.flycrispr.neuro.brown.edu) and cloned into pCFD5 plasmid following the pCFD5 cloning protocol (www.crisprflydesign.com) using the primers $5^{\prime}$-gcggccegggttcgattcccggccgatgcagaagatctagaattagatatgttttagagctagaaatagcaag-3' and $5^{\prime}$-attttaacttgctatttctagctctaaaaccacttcgtgattaattctgatgcaccagccgggaatcgaaccc-3' [125]. To precisely delete the TE sequence, a donor DNA containing two homology arms flanking the DsRed sequence for homology repair were cloned into the pHD-ScarlessDsRed plasmid using Q5 $5^{\circ}$ High-Fidelity DNA Polymerase (New England Biolabs). Left homology arm contained the sequence in 3R:16188287-16189463, while right homology arm contained the sequence in 3R:16189811-16191083 (Release 6) from the outbred population with FBti0019386. To avoid cleavage of the donor construct and mutagenesis after integration by CRISPR/Cas9, two single-nucleotide synonymous substitutions ( $\mathrm{G}>\mathrm{T}$ for sgRNA1 site; $\mathrm{G}>\mathrm{T}$ for sgRNA2 site) were introduced into the 
two sgRNA target site PAM sequences, respectively. The pCFD5 plasmid containing the gRNAs, the donor pHD-ScarlessDsRed plasmid containing the homology arms, and a plasmid containing Cas9 endonuclease were co-injected as a unique mix into approximately 550 pre-blastoderm embryos from the outbred population with FBti0019386. All the injections were performed using the following mix concentrations: pCFD5 plasmid at $100 \mathrm{ng} / \mu \mathrm{l}$, donor plasmid at $500 \mathrm{ng} / \mu \mathrm{l}$, and Cas 9 plasmid at $250 \mathrm{ng} / \mu \mathrm{l}$. Offspring was screened for eye fluorescence, and flies containing the deletion were backcrossed with the parental line for a minimum of five generations. Then, two homozygous strains containing the deletion of FBti0019386 were established: FBti0019386-A1 and FBti0019386-A2. The deletion was checked by PCR with the primers $5^{\prime}$ - tttggaatcaatcacatcaaccc $-3^{\prime}$ and $5^{\prime}$-caatgtcctgggtgtaagtctcg-3'. PCR bands were confirmed by Sanger sequencing.

\section{Transposable element datasets}

\section{TEs annotated in the reference genome}

There are 5416 TEs annotated in the release 6 of the D. melanogaster reference genome (73). In this work, we focused on polymorphic TEs present at high population frequencies and located in regions of the genome with recombination rate larger than zero [49]. Most TE insertions are expected to be deleterious. Due to its big effective population size, we expect most TE insertions to be present at low frequencies in D. melanogaster. Thus, TEs present at high population frequencies are likely to be adaptive. We did not consider the 2234 INE-1 insertions that are fixed in D. melanogaster populations [126-128]. We also discarded 1561 TEs that are flanked by simple repeats, nested TEs, or TEs that are part of segmental duplications because frequencies cannot be accurately estimated for these TEs using T-lex2 [50]. Finally, we discarded 813 TEs present in genomic regions with a recombination rate $=0$ according to Fiston-Lavier et al. (2010) [129] or Comeron et al. (2012) [130]. TEs present at low recombination regions are more likely to be linked to an adaptive mutation rather than being the causal mutation [131-134]. Moreover, the efficiency of selection is low in these regions and, thus, slightly deleterious TEs could have reached high frequencies [135, 136]. Hence, we ended up with a dataset of 808 annotated TEs for which we estimated their population frequencies using T-lex2 [50] (Additional file 1A).

Two hundred thirty-one of the 808 annotated TEs were fixed in the four populations studied. Although some of these fixed TEs might be adaptive, we did not consider them as we cannot perform comparative functional experiments between natural flies with and without the insertions. We considered high frequent TEs those present at a population frequency $\geq 10 \%$ : 109 TEs. Note that varying this threshold does not substantially alter the number of TEs present at high frequencies (e.g., 95 TEs if we consider $\geq 15 \%$ ).

\section{Non-reference TE insertions}

We also analyzed a subset of TEs identified by Rahman et al. (2015) [51] in DGRP strains that are not annotated in the reference genome (Additional file 1B). We analyzed 23 TEs that are present in regions with recombination rate $>0[129,130]$ and were inferred to be present in at least 15 DGRP strains out of the 177 strains analyzed by Rahman et al. (2015) [51]. We obtained from Bloomington Drosophila Stock Center 
(BDSC) all the strains carrying each of the 23 insertions, and we confirmed by PCR the presence of the insertions in several strains (see below). For each TE, we sequenced at least one of the PCR products to confirm the presence and the family identity of the TE. For those insertions that we could verify, we estimated the frequency of each TE based on TIDAL results in the 177 DGRP strains and considered as high frequent those present at a population frequency $\geq 10 \%$.

\section{Presence/Absence of TEs in the analyzed strains}

We performed PCRs to confirm the in silico results obtained with T-lex2 [50] and TIDAL [51]. We designed specific primers for each analyzed TE using the online software Primer-BLAST [137] (Additional file 5). Briefly, we designed a primer pair flanking the TE (FL and R primers), which produces a PCR product with different band sizes when the TE is present and when the TE is absent. For those TEs that are present in the reference genome, we also designed a primer inside the TE sequence (L primer) that, combined with the $\mathrm{R}$ primer, only amplifies when the TE is present [138]. To perform the PCRs, genomic DNA was extracted from 10 females from each analyzed strain.

\section{Functional annotation of genes nearby candidate adaptive TEs}

We looked for functional information of the genes associated to the TEs present at high population frequencies using FlyBase [106]. We considered all the genes that were located less than $1 \mathrm{~kb}$ from the TEs. If the TEs did not have any gene located in the 1 $\mathrm{kb}$ flanking regions, we considered only the closest gene. We considered GO annotations based on experimental evidence, and we also obtained functional information based on the publications cited in FlyBase. Several lines of evidence were considered: genome-wide association studies in which SNPs in the analyzed genes were linked to a phenotypic trait, differential expression analyses, and phenotypic evidence based on the analyses of mutant strains (Additional file 1D).

\section{P. entomophila infection}

We infected 5- to 7-day-old female flies with the gram-negative bacteria P. entomophila [46]. Flies were separated into food vials under $\mathrm{CO}_{2}$ anesthesia 2 days before the bacteria exposure and were kept at $25^{\circ} \mathrm{C}$. The experiments were performed as described in Neyen et al. (2014) [139]. Briefly, flies were starved for $2 \mathrm{~h}$, and then they were flipped to a food vial containing a filter paper soaked with $1.25 \%$ of sucrose and bacterial pellet. The bacterial preparation was adjusted to a final $\mathrm{OD}_{600}=100$, corresponding to $6.5 \times$ $10^{10}$ colony forming units per $\mathrm{ml}[140]$. Flies were kept at $29^{\circ} \mathrm{C}$ (only $12 \mathrm{~h}$ for gene expression analysis) and $70 \%$ humidity, which are the optimal infection conditions for $P$. entomophila. In parallel, we exposed non-infected flies to sterile LB with $1.25 \%$ sucrose.

\section{Gene expression analysis}

For RNA extraction, three replicates of 20-30 5- to 7-day-old females, males, or female guts from each gene disruption, RNAi, overexpressing and wild-type strain were flashfrozen in liquid nitrogen and stored at $-80^{\circ} \mathrm{C}$ until sample processing (Additional file 2A). For each gene, RNA extraction was performed in the tissue and sex that FlyBase 
database reported a higher gene expression (Additional file 2A). For gene expression analysis after infection (in isofemale/inbred, outbred, and CRISPR/Cas9 mutant strains), we dissected 20-30 guts from both non-infected and infected 5- to 7-day-old females. Flies were infected with the gram-negative bacteria $P$. entomophila as mentioned above, and they were dissected after $12 \mathrm{~h}$ of bacterial exposure. Samples were flash frozen in liquid nitrogen and stored at $-80^{\circ} \mathrm{C}$ until sample processing. RNA was extracted using the GenElute $^{\text {Tu }}$ Mammalian Total RNA Miniprep Kit (Merck) following manufacturer's instructions. RNA was then treated with DNase I (Thermo). cDNA was synthesized from a total of 250-1000 ng of RNA using the NZY First-Strand cDNA synthesis kit (NZYTech). Primers used for qRT-PCR experiments are listed in Additional file 2D. In all the cases, gene expression was normalized with the housekeeping gene Act5c (primers: 5'-gcgcccttactctttcacca-3' and 5'-atgtcacggacgatttcacg-3'. We performed the qRT-PCR analysis with SYBR Green (BioRad) or qPCRBIO SyGreen Blue Mix LO-ROX (PCR BIOSYSTEMS) on an iQ5 Thermal cycler or CFX Real-Time PCR, respectively. Results were analyzed using the $\mathrm{dCT}$ method following the recommendations of the MIQE guideline [141].

\section{Infection survival assays}

We performed infection survival assays with gene disruption, RNAi, overexpression strains comparing their mortality to the mortality of strains with similar genetic backgrounds (Additional file 2A). We also performed infection survival experiments using outbred flies with and without FBti0019386 and CRISPR/Cas9 mutant flies FBti0019386-A1 and FBti0019386-A2. Female flies were placed in groups of 10 per vial, and we performed the experiments with 5-12 vials (Additional file $2 \mathrm{C}$ ), except for $\mathrm{cn}^{1}$ considered as a wild-type background for which we used 3 vials. Flies were orally infected with $P$. entomophila as explained above. As a control for each experiment, we exposed 3-4 vials containing 10 flies each to sterile LB with $1.25 \%$ sucrose. Fly mortality was monitored at several time points until all the flies were dead. Survival curves were analyzed with log-rank test using SPSS v21 software. If the test was significant, we calculated the odds ratio and its $95 \%$ confidence interval when $50 \%$ of the susceptible flies were dead, except for CG8008 and $c b x$ that was estimated when 30\% and 96\% of the susceptible flies were dead.

\section{Allele-specific expression analysis (ASE)}

For each TE analyzed, we first identified two strains homozygous for the presence and two strains homozygous for the absence of the TE according to T-lex2 or TIDAL [50, 51]. We then looked for a synonymous SNP linked to the presence of the TE and located in the coding region of the nearby gene. Note that we only selected a SNP when it is present in the coding region of all the alternative transcripts described for that gene. To select the SNP, we downloaded the coding region of the nearby gene from the sequenced DGRP strains available in http://popdrowser.uab.cat/ [142]. Once we identified a diagnostic SNP, we re-sequenced the region identified in the used strains to confirm the presence of the SNP, and we performed a PCR to confirm the presence or the absence of the TE. We selected a synonymous SNP that is not linked to the TE in any of the strains analyzed (Additional file 6A). We also analyzed the coding region of the 
gene in order to discard the presence of nonsynonymous SNPs that could be linked to the TE (Additional file 6B). Additionally, we analyzed the flanking regions of each TE in order to discard other variants that could be linked to the TE or that could be potentially modifying the gene regulatory regions (Additional file $6 \mathrm{C}$ ). To do this, we used VISTA to define the conserved regions in the $1 \mathrm{~kb}$ TE flanking sequences between $D$. melanogaster and D. yakuba, which diverged approximately 11.6 Mya [143]. We then checked whether there is any SNP linked to the presence of the TE in the DGRP strains. Only for the $A G O 2$ gene, we found two SNPs in the coding region that were linked to the TE insertion (Additional file 6B). AGO2 is a gene showing a fast rate of adaptive amino acid substitutions [107, 144], and it is associated with a recent selective sweep [107]. However, it is still not clear which is the genetic variant that is under positive selection [107]. Thus, for 13 out of the 14 TEs analyzed, we could not detect any other polymorphism that could be responsible for the observed allele-specific expression differences suggesting that the TE is the most likely causal mutation.

We were not able to analyze five of the candidate TEs: for three TEs, FBti0019381, FBti0061105, and FBti0062242, we could not identify homozygous strains with and without the TE. For FBti0019564, we could not identify a diagnostic SNP. Finally, for $t d n 17$, we could not design primers to validate the diagnostic SNP due to the presence of repetitive sequences in the nearby gene.

We then crossed a strain with the TE with a strain without the TE differing by the diagnostic SNP to obtain heterozygous flies in which allele-specific expression was measured (Additional file 6A). Note that for each TE two crosses were performed so that ASE was measured in two different genetic backgrounds. ASE was measured in non-infected and infected conditions. We obtained cDNA samples from three biological replicates. We also extracted genomic DNA (gDNA) from 15 to 20 heterozygous females for each cross, which is needed to correct for any bias in PCR-amplification between alleles [145]. cDNA and gDNA samples were sent to an external company for primer design and pyrosequencing. We analyzed the pyrosequencing results as described in Wittkopp et al. (2011) [145]. Briefly, we calculated the ratios of the allele with the TE and the allele without the TE of the cDNA samples, and we normalized the values with the gDNA ratio. In order to perform the statistical analysis, we transformed the ratios with log2, and we applied a twotailed $t$ test in order to check whether there were allele expression differences between the alleles. We corrected the $p$ values for multiple testing using Benjamini-Hochberg's false discovery rate (5\% FDR) [146].

\section{Chromatin immunoprecipitation-qPCR}

We performed ChIP-qPCR experiments to detect whether TEs associated with allelespecific lower expression were adding H3K9me3 repressive marks [100, 101]. For that, we compared the histone mark levels in homozygous flies with the TE with the levels in homozygous flies without the TE. We used $\mathrm{y}^{1} ; \mathrm{cn}^{1} \mathrm{bw}^{1} \mathrm{sp}^{1}$ strain [147], the strain that was sequenced to obtain the $D$. melanogaster reference genome sequence [148-150], as the homozygous strain with FBti0020057, FBti0018883, FBti0018877, FBti0019985, and FBti0020137 insertions, and RAL-908, as the homozygous strain without those insertions [123]. We also checked H3K9me3 marks in $t d n 4$ using $\mathrm{y}^{1} ; \mathrm{cn}^{1} \mathrm{bw}^{1} \mathrm{sp}^{1}$ strain as homozygous for the absence and $R A L-810$ homozygous for the presence of the 
insertion. We first confirmed by PCR the presence or absence of each insertion in the strains used. To detect H3K9me3 levels associated to the TE, we designed primer pairs in the TE flanking regions ("left" and "right"): one primer inside the TE sequence and one primer outside the TE sequence (Additional file 7). To detect H3K9me3 levels in the strains without the TE, we used the left forward primer and the right reverse primer. Primer efficiencies ranged from 90 to $110 \%$. We used a total of $45-55$ guts per strain and we performed three biological replicates for each. To obtain the chromatin, we followed Magna-Chip ${ }^{\mathrm{TM}}$ A/G kit (from Merck) protocol. After dissection, we homogenized the samples in the buffer A1 with a dounce 30 times, and we crosslinked the guts using formaldehyde at a final concentration of $1.8 \%$ for $10 \mathrm{~min}$ at room temperature. We stopped the crosslink by adding glycine at a final concentration of $125 \mathrm{mM}$; we incubated samples $3 \mathrm{~min}$ at room temperature and kept them on ice. Then, we washed the samples three times with buffer A1, and we incubated the sample for $3 \mathrm{~h}$ at $4{ }^{\circ} \mathrm{C}$ with $0.2 \mathrm{ml}$ of lysis buffer. After lysis, we sonicated the samples using Biorruptor ${ }^{\ominus}$ pico sonication device from Diagenode: 14 cycles of 30 s ON, 30 s OFF. We kept $20 \mu \mathrm{l}$ of input chromatin for the analysis (see below), and we immunoprecipitated $80 \mu \mathrm{l}$ of the remaining sample with antibody against H3K9me3 (\#ab8898 from Abcam). As a control for the immunoprecipitation, we checked the H3K9me3 levels in the genes $18 S$ and Rpl32 that are expected to be, respectively, enriched and depleted for this histone mark (Additional file 7). We quantified the immunoprecipitation enrichment by qRT-PCR normalizing the data using the "input" of each IP as the reference value using the $\mathrm{dCT}$ method as mentioned before.

\section{In vivo gene reporter assays}

We generated transgenic flies carrying the TE sequence in front of the lacZ reporter gene by using the placZ.attB vector (accession number: KC896840) [151]. In order to construct a clone with the correct orientation in the promoter region of lacZ, two cloning steps were necessary. We first had to introduce specific restriction sites into the flanking regions for each TE sequence. For that, we introduced the restriction sites with the primers used to amplify the region containing the TE sequence (Additional file 8). We used a high fidelity Taq DNA polymerase for DNA amplification (Expand High Fidelity PCR system from Sigma). After that, we cloned the PCR product into the vector pCR4-TOPO $^{\circ}$ (Invitrogen). Finally, we digested both vectors and ligated the TE sequence into the placZ.attB, and we sequenced the cloned insert to ensure that no polymerase errors were introduced in the PCR step. We purified the vector with the GeneEluteTM Plasmid Miniprep kit (Sigma) and prepared the injection mix at $300 \mathrm{ng} /$ $\mu \mathrm{l}$ vector concentration diluted with injection buffer $(5 \mathrm{mM} \mathrm{KCl}, 0.1 \mathrm{mM}$ sodium phosphate, $\mathrm{pH}$ 6.8). The injection mix was sent to an external company to inject embryos from a strain that contain a stable integration site (Bloomington stock \#24749). After microinjection, surviving flies were crossed in pairs and the offspring was screened for red eye color, which was diagnostic for stable mutants. We established three transgenic strains for each analyzed TE, which were considered as biological replicates in the expression experiments. As a negative control, we also established transgenic strains with the placZ.attB empty vector, in order to control for possible lac $Z$ expression driven by the vector sequence. 
For FBti0018868, we designed primers flanking the TE and cloned the PCR product in front of the lacZ reporter gene (Additional file 8). For the other two TEs, we constructed two different clones to generate two transgenic strains: one strain with the TE and the other strain without the TE. For the TE FBti0061506, which spans only $48 \mathrm{bp}$, one strain carries the TE and part of the flanking intronic region, and the other strain contains the same genomic region without the TE. For the TE $t d n 8$, one strain carries the upstream region of CG10943, including the 5'UTR, with $t d n 8$, and the other strain carries the same genomic region without $t d n 8$. Finally, for the TE FBti0020057, we cloned the whole intergenic region, including the UTRs of the flanking genes (Additional file 8).

For the transgenic strains generated in the in vivo enhancer assays, we checked lacZ expression in female guts in non-infected and infected conditions. We used the forward primer 5 '-cctgctgatgaagcagaacaact- 3 ', and reverse primer $5{ }^{\prime}$-gctacggcctgtatgtggtg-3' to check lacZ expression. Gene expression was normalized with the housekeeping gene Act $5 c$. We performed all RNA extractions, cDNA synthesis and qRT-PCR analysis as mentioned above.

\section{Immunofluorescence staining}

We performed immunofluorescence gut staining to localize $\beta$-GAL expression in the transgenic flies from the enhancer assays, both in non-infected and infected conditions. Flies were dissected and gut tissue was fixed with $4 \%$ Formaldehyde. The tissue was then stained by using the primary antibody mouse anti- $\beta$ Galactosidase (Hybridoma bank 40-1a) and the secondary antibody anti-mouse Alexa Fluor 555 (Sigma). Images were analyzed and captured using a Leica SP5 confocal microscope.

\section{Transcription factor binding site mutagenesis}

Mutagenesis of the binding sites for the predicted Caudal and DEAF-1 transcription factors was performed sequentially with the Q5 Site-Directed Mutagenesis kit (New England Biolabs) taking as a template the pGreenRabbit vector containing the FBti0019386 sequence following manufacturer's instructions [25]. To perform the Caudal binding site mutagenesis, we used the primer pair 5' -actcgatcggacctcact-3' and 5'gtgtgttagagagagatgacaatg- $3^{\prime}$. To perform the DEAF-1 binding site mutagenesis, we used the primer pair $5^{\prime}$-cctctgccgcagcgctcg-3' and $5^{\prime}$-cagcctctgcagctgagtgagg- $3^{\prime}$. Deletions were checked by PCR with the primers $5^{\prime}$-cgacgtgttcactttgcttgt- $3^{\prime}$ and $5^{\prime}$-gtaccttcaaataccettggatcg-3'. PCR bands were confirmed by Sanger sequencing. Vector purification, injection mix preparation, embryo microinjection, and fly strain generation were performed as explained above. We then checked Gfp expression in female guts in control and infected conditions. We used the forward primer $5^{\prime}$-atgatcagcgagttgcacgcc- 3 ', and reverse primer 5' -gacggaaacatcctcggccaca-3' to check Gfp expression. Gene expression was normalized with the housekeeping gene $A c t 5 c$. We performed all RNA extractions, cDNA synthesis and qRT-PCR analysis as mentioned above.

\section{Detection of alternative transcripts}

To confirmed whether Bin1 transcripts starts in FBti0019386, as reported by Batut et al. (2013) [24], we performed RT-PCR in the gut tissue of non-infected and infected 
flies. We used the forward primer $5^{\prime}$-atctgaagctcgttggtggg-3' and the reverse primer $5^{\prime}$-atgagactcctgtttcgccg- $3^{\prime}$ to detect Bin1 transcript starting in the TE, and the same forward primer with the reverse primer $5^{\prime}$-aagagcaaagagaagccggaa-3' to detect Bin1 short transcript.

\section{Supplementary Information}

The online version contains supplementary material available at https://doi.org/10.1186/s13059-021-02471-3.

Additional file 1: 1A.) Reference TE dataset present in genomic regions with recombination rate larger than zero. 1B.) Non-reference TE insertions. 1C.) Candidate adaptive TE dataset. 1D.) Gene functional information for the genes nearby candidate adaptive TEs. 1E.) Immune-related TFBS found in the TEs analyzed in the ASE experiments as reported by Villanueva-Cañas et al (2019).

Additional file 2: 2A.) Genotype information on the gene disruption, overexpression, and RNAi stocks used in this work, and summary of the expression and survival assays results. 2B.) Expression results (qRT-PCR) for the gene disruption, overexpression, and RNAi stocks used in this work. 2C.) Survival assay results for the gene disruption, overexpression, and RNAi stocks used in this work. 2D.) Primers used for the gRT-PCR analysis.

Additional file 3. Allele ratios from the allele-specific expression (ASE) analysis.

Additional file $4 \mathrm{D}$. melanogaster strains used in the different experiments.

Additional file 5. Primers used for the TE screening analysis.

Additional file 6: 6A.) Fly strains and SNPs used in the ASE crosses for each gene. 6B.) Analysis of the SNPs in the coding regions of the genes analyzed in the ASE. $\mathbf{6 C}$.) Analysis of the $1 \mathrm{~kb}$ TE flanking regions (upstream and downstream) conserved between D. melanogaster and D. yakuba.

Additional file 7 Primers used for ChIP RT-qPCR experiments and H3K9me3 levels in the genes 185 and Rp/32.

Additional file 8. Primers used for the amplification of the genomic regions analyzed in the enhancer assays.

Additional file 9. Review history.

\section{Acknowledgements}

We thank members of the González lab for comments on the manuscript.

\section{Review history}

The review history is available as Additional file 9

\section{Peer review information}

Tim Sands was the primary editor of this article and managed its editorial process and peer review in collaboration with the rest of the editorial team.

\section{Authors' contributions}

A.U., M.M., and J.G. designed and managed the project. A.U. and M.M. performed the experiments. A.U., M.M., and J.G. analyzed the data and wrote the paper. J.G. revised the paper. All authors read and approved the final manuscript.

\section{Funding}

This project has received funding from the European Research Council (ERC) under the European Union's Horizon 2020 research and innovation program (H2020-ERC-2014-CoG-647900) and under the FP7 program (FP7-PEOPLE-2011CIG-293860) and by the MEC/FEDER (BFU2014-57779-P). A.U. was a FPI fellow (BES-2012-052999) and JG was a Ramon y Cajal fellow (RYC-2010-07306). The funding bodies had no role in the design of the study and collection, analysis, and interpretation of data or in writing the manuscript.

\section{Availability of data and materials}

The datasets supporting the conclusions of this article are included within the article and its additional files.

\section{Declarations}

Ethics approval and consent to participate

Not applicable.

\section{Consent for publication}

Not applicable.

\section{Competing interests}

The authors declare no competing interests. 
Received: 29 October 2020 Accepted: 19 August 2021

Published online: 14 September 2021

\section{References}

1. Buchberger E, Reis M, Lu TH, Posnien N. Cloudy with a chance of insights: context dependent gene regulation and implications for evolutionary studies. Genes (Basel). 2019;10(7):492. https://doi.org/10.3390/genes10070492.

2. Andersson $\mathrm{R}$, Sandelin A. Determinants of enhancer and promoter activities of regulatory elements. Nat Rev Genet. 2020;21(2):71-87.

3. Romero IG, Ruvinsky I, Gilad Y. Comparative studies of gene expression and the evolution of gene regulation. Nat Rev Genet. 2012;13(7):505-16. https://doi.org/10.1038/nrg3229.

4. Gisselbrecht SS, Palagi A, Kurland JV, Rogers JM, Ozadam H, Zhan Y, et al. Transcriptional silencers in Drosophila serve a dual role as transcriptional enhancers in alternate cellular contexts. Mol Cell. 2020;77(2):324-37.e8.

5. Doni Jayavelu N, Jajodia A, Mishra A, Hawkins RD. Candidate silencer elements for the human and mouse genomes. Nat Commun. 2020;11(1):1061. https://doi.org/10.1038/s41467-020-14853-5.

6. Rojano E, Seoane P, Ranea JAG, Perkins JR. Regulatory variants: from detection to predicting impact. Brief Bioinform. 2019;20(5):1639-54. https://doi.org/10.1093/bib/bby039.

7. Rebollo R, Romanish MT, Mager DL. Transposable elements: an abundant and natural source of regulatory sequences for host genes. Annu Rev Genet. 2012;46(1):21-42. https://doi.org/10.1146/annurev-genet-110711-155621.

8. Elbarbary RA, Lucas BA, Maquat LE. Retrotransposons as regulators of gene expression. Science. 2016;351(6274):aac7247.

9. Chuong EB, Elde NC, Feschotte C. Regulatory activities of transposable elements: from conflicts to benefits. Nat Rev Genet. 2017;18(2):71-86. https://doi.org/10.1038/nrg.2016.139.

10. Sundaram $V$, Wang T. Transposable element mediated innovation in gene regulatory landscapes of cells: re-visiting the "gene-battery" model. Bioessays. 2018;40(1). https://doi.org/10.1002/bies.201700155.

11. Moschetti R, Palazzo A, Lorusso P, Viggiano L, Marsano RM. "What you need, baby, i got it": transposable elements as suppliers of cis-operating sequences in Drosophila. Biology (Basel). 2020;9(2): 25. https://doi.org/10.3390/biology9020025.

12. Sundaram V, Wysocka J. Transposable elements as a potent source of diverse. Philos Trans R Soc Lond B Biol Sci. 2020; 375(1795):20190347. https://doi.org/10.1098/rstb.2019.0347.

13. Bourque G, Burns KH, Gehring M, Gorbunova V, Seluanov A, Hammell M, et al. Ten things you should know about transposable elements. Genome Biol. 2018;19(1):199. https://doi.org/10.1186/s13059-018-1577-z.

14. Chuong EB, Elde NC, Feschotte C. Regulatory evolution of innate immunity through co-option of endogenous retroviruses. Science. 2016;351(6277):1083-7.

15. Barco B, Kim Y, Clay NK. Expansion of a core regulon by transposable elements promotes Arabidopsis chemical diversity and pathogen defense. Nat Commun. 2019;10(1):3444. https://doi.org/10.1038/s41467-019-11406-3.

16. Choi JY, Lee YCG. Double-edged sword: the evolutionary consequences of the epigenetic silencing of transposable elements. PLoS Genet. 2020;16(7):e1008872. https://doi.org/10.1371/journal.pgen.1008872.

17. Faulkner GJ, Carninci P. Altruistic functions for selfish DNA. Cell Cycle. 2009;8(18):2895-900. https://doi.org/10.4161/cc.8.1 8.9536.

18. Trizzino M, Park Y, Holsbach-Beltrame M, Aracena K, Mika K, Caliskan M, et al. Transposable elements are the primary source of novelty in primate gene regulation. Genome Res. 2017;27(10):1623-33. https://doi.org/10.1101/gr.218149.116

19. Cao X, Zhang Y, Payer LM, Lords H, Steranka JP, Burns KH, et al. Polymorphic mobile element insertions contribute to gene expression and alternative splicing in human tissues. Genome Biol. 2020;21(1):185.

20. Miao B, Fu S, Lyu C, Gontarz P, Wang T, Zhang B. Tissue-specific usage of transposable element-derived promoters in mouse development. Genome Biol. 2020;21(1):255. https://doi.org/10.1186/s13059-020-02164-3.

21. Pontis J, Planet E, Offner S, Turelli P, Duc J, Coudray A, et al. Hominoid-specific transposable elements and KZFPS facilitate human embryonic genome activation and control transcription in naive human ESCs. Cell Stem Cell. 2019; 24(5):724-35.e5.

22. Fuentes DR, Swigut T, Wysocka J. Systematic perturbation of retroviral LTRs reveals widespread long-range effects on human gene regulation. Elife. 2018;7. https://doi.org/10.7554/eLife.35989.

23. Todd CD, Deniz Ö, Taylor D, Branco MR. Functional evaluation of transposable elements as enhancers in mouse embryonic and trophoblast stem cells. Elife. 2019;8. https://doi.org/10.7554/eLife.44344.

24. Batut P, Dobin A, Plessy C, Carninci P, Gingeras TR. High-fidelity promoter profiling reveals widespread alternative promoter usage and transposon-driven developmental gene expression. Genome Res. 2013;23(1):169-80.

25. Villanueva-Cañas $J$, Horvath V, Aguilera L, González J. Diverse families of transposable elements affect the transcriptional regulation of stress-response genes in Drosophila melanogaster. Nucleic Acids Res. 2019;47(13):6842-57. https://doi.org/10.1093/nar/gkz490.

26. Rebollo R, Karimi MM, Bilenky M, Gagnier L, Miceli-Royer K, Zhang Y, et al. Retrotransposon-induced heterochromatin spreading in the mouse revealed by insertional polymorphisms. PLoS Genet. 2011;7(9):e1002301. https://doi.org/10.13 71/journal.pgen.1002301.

27. Garcia-Perez JL, Widmann TJ, Adams IR. The impact of transposable elements on mammalian development. Development. 2016;143(22):4101-14. https://doi.org/10.1242/dev.132639.

28. Pehrsson EC, Choudhary MNK, Sundaram V, Wang T. The epigenomic landscape of transposable elements across normal human development and anatomy. Nat Commun. 2019;10(1):5640. https://doi.org/10.1038/s41467-019-13555-x.

29. Salces-Ortiz J, Vargas-Chavez C, Guio L, Rech GE, González J. Transposable elements contribute to the genomic response to insecticides in. Philos Trans R Soc Lond B Biol Sci. 2020;375(1795):20190341. https://doi.org/10.1098/rstb.2019.0341.

30. Ye M, Goudot C, Hoyler T, Lemoine B, Amigorena S, Zueva E. Specific subfamilies of transposable elements contribute to different domains of T lymphocyte enhancers. Proc Natl Acad Sci U S A. 2020;117(14):7905-16. https://doi.org/10.1 073/pnas.1912008117.

31. Bogdan L, Barreiro L, Bourque G. Transposable elements have contributed human regulatory regions that are activated upon bacterial infection. Philos Trans R Soc Lond B Biol Sci. 2020;375(1795):20190332. https://doi.org/10.1098/rstb.2019. 0332 . 
32. Deniz Ö, Ahmed M, Todd CD, Rio-Machin A, Dawson MA, Branco MR. Endogenous retroviruses are a source of enhancers with oncogenic potential in acute myeloid leukaemia. Nat Commun. 2020;11(1):3506.

33. Ivancevic A, Chuong EB. Transposable elements teach T cells new tricks. Proc Natl Acad Sci U S A. 2020;117(17):9145-7. https://doi.org/10.1073/pnas.2004493117.

34. Hoffmann JA, Reichhart JM. Drosophila innate immunity: an evolutionary perspective. Nat Immunol. 2002;3(2):121-6. https://doi.org/10.1038/ni0202-121.

35. Quintana-Murci L, Clark AG. Population genetic tools for dissecting innate immunity in humans. Nat Rev Immunol. 2013; 13(4):280-93. https://doi.org/10.1038/nri3421.

36. Bonfini A, Liu X, Buchon N. From pathogens to microbiota: how Drosophila intestinal stem cells react to gut microbes. Dev Comp Immunol. 2016;64:22-38. https://doi.org/10.1016/j.dci.2016.02.008.

37. Capo F, Charroux B, Royet J. Bacteria sensing mechanisms in Drosophila gut: local and systemic consequences. Dev Comp Immunol. 2016;64:11-21. https://doi.org/10.1016/j.dci.2016.01.001.

38. Buchon N, Broderick NA, Poidevin M, Pradervand S, Lemaitre B. Drosophila intestinal response to bacterial infection: activation of host defense and stem cell proliferation. Cell Host Microbe. 2009;5(2):200-11. https://doi.org/10.1016/j. chom.2009.01.003.

39. Kayama H, Takeda K. Functions of innate immune cells and commensal bacteria in gut homeostasis. J Biochem. 2016; 159(2):141-9.

40. Lazzaro BP, Rolff J. Immunology. Danger, microbes, and homeostasis. Science. 2011;332(6025):43-4. https://doi.org/1 $0.1126 /$ science. 1200486 .

41. Bou Sleiman MS, Osman D, Massouras A, Hoffmann AA, Lemaitre B, Deplancke B. Genetic, molecular and physiological basis of variation in Drosophila gut immunocompetence. Nat Commun. 2015;6(1):7829. https://doi.org/10.1038/ ncomms8829.

42. Fairfax BP, Humburg P, Makino S, Naranbhai V, Wong D, Lau E, et al. Innate immune activity conditions the effect of regulatory variants upon monocyte gene expression. Science. 2014;343(6175):1246949. https://doi.org/10.1126/ science.1246949.

43. Lee MN, Ye C, Villani A-C, Raj T, Li W, Eisenhaure TM, et al. Common genetic variants modulate pathogen-sensing responses in human dendritic cells. Science. 2014;343(6175):1246980.

44. Piasecka B, Duffy D, Urrutia A, Quach H, Patin E, Posseme C, et al. Distinctive roles of age, sex, and genetics in shaping transcriptional variation of human immune responses to microbial challenges. Proc Natl Acad Sci U S A. 2018;115(3): E488-E97. https://doi.org/10.1073/pnas.1714765115.

45. Frochaux MV, Bou Sleiman M, Gardeux V, Dainese R, Hollis B, Litovchenko M, et al. cis-regulatory variation modulates susceptibility to enteric infection in the Drosophila genetic reference panel. Genome Biol. 2020;21(1):6.

46. Vodovar N, Vinals M, Liehl P, Basset A, Degrouard J, Spellman P, et al. Drosophila host defense after oral infection by an entomopathogenic Pseudomonas species. Proc Natl Acad Sci U S A. 2005;102(32):11414-9. https://doi.org/10.1073/pnas. 0502240102.

47. Sackton TB, Lazzaro BP, Clark AG. Genotype and gene expression associations with immune function in Drosophila. PLoS Genet. 2010;6(1):e1000797. https://doi.org/10.1371/journal.pgen.1000797.

48. Teixeira L. Whole-genome expression profile analysis of Drosophila melanogaster immune responses. Brief Funct Genomics. 2012;11(5):375-86.

49. Haddrill PR, Halligan DL, Tomaras D, Charlesworth B. Reduced efficacy of selection in regions of the Drosophila genome that lack crossing over. Genome Biol. 2007;8(2):R18. https://doi.org/10.1186/gb-2007-8-2-r18.

50. Fiston-Lavier AS, Barrón MG, Petrov DA, González J. T-lex2: genotyping, frequency estimation and re-annotation of transposable elements using single or pooled next-generation sequencing data. Nucleic Acids Res. 2015;43(4):e22. https://doi.org/10.1093/nar/gku1250.

51. Rahman R, Chirn GW, Kanodia A, Sytnikova YA, Brembs B, Bergman CM, et al. Unique transposon landscapes are pervasive across Drosophila melanogaster genomes. Nucleic Acids Res. 2015;43(22):10655-72. https://doi.org/10.1093/na r/gkv1193.

52. Rech GE, Bogaerts-Márquez M, Barrón MG, Merenciano M, Villanueva-Cañas JL, Horváth V, et al. Stress response, behavior, and development are shaped by transposable element-induced mutations in Drosophila. PLoS Genet. 2019; 15(2):e1007900. https://doi.org/10.1371/journal.pgen.1007900.

53. Levy S, Shoham T. The tetraspanin web modulates immune-signalling complexes. Nat Rev Immunol. 2005;5(2):136-48. https://doi.org/10.1038/nri1548.

54. Myllymäki H, Rämet M. JAK/STAT pathway in Drosophila immunity. Scand J Immunol. 2014;79(6):377-85. https://doi. org/10.1111/sji.12170.

55. Keebaugh ES, Schlenke TA. Insights from natural host-parasite interactions: the Drosophila model. Dev Comp Immunol. 2014;42(1):111-23. https://doi.org/10.1016/j.dci.2013.06.001.

56. Kallio J, Leinonen A, Ulvila J, Valanne S, Ezekowitz RA, Rämet M. Functional analysis of immune response genes in Drosophila identifies JNK pathway as a regulator of antimicrobial peptide gene expression in S2 cells. Microbes Infect. 2005;7(5-6):811-9.

57. Kleino A, Valanne S, Ulvila J, Kallio J, Myllymäki H, Enwald H, et al. Inhibitor of apoptosis 2 and TAK1-binding protein are components of the Drosophila Imd pathway. EMBO J. 2005;24(19):3423-34. https://doi.org/10.1038/sj.emboj.7600807.

58. Kim T, Yoon J, Cho H, Lee W-B, Kim J, Song Y-H, et al. Downregulation of lipopolysaccharide response in drosophila by negative crosstalk between the AP1 and NF-KB signaling modules. Nat Immunol. 2005;6:211.

59. Blumenstiel JP, Chen X, He M, Bergman CM. An age-of-allele test of neutrality for transposable element insertions. Genetics. 2014;196(2):523-38. https://doi.org/10.1534/genetics.113.158147.

60. De Gregorio E, Spellman PT, Tzou P, Rubin GM, Lemaitre B. The Toll and Imd pathways are the major regulators of the immune response in Drosophila. EMBO J. 2002;21(11):2568-79.

61. Chakrabarti S, Liehl P, Buchon N, Lemaitre B. Infection-induced host translational blockage inhibits immune responses and epithelial renewal in the Drosophila gut. Cell Host Microbe. 2012;12(1):60-70. https://doi.org/10.1016/j.chom.2012. 06.001 . 
62. Huang Z, Kingsolver MB, Avadhanula V, Hardy RW. An antiviral role for antimicrobial peptides during the arthropod response to alphavirus replication. J Virol. 2013;87(8):4272-80. https://doi.org/10.1128/JVI.03360-12.

63. Erkosar B, Erkosar Combe B, Defaye A, Bozonnet N, Puthier D, Royet J, et al. Drosophila microbiota modulates host metabolic gene expression via IMD/NF-kB signaling. PLoS One. 2014;9(4):e94729. https://doi.org/10.1371/journal.pone. 0094729.

64. Roxström-Lindquist K, Terenius O, Faye I. Parasite-specific immune response in adult Drosophila melanogaster: a genomic study. EMBO Rep. 2004;5(2):207-12. https://doi.org/10.1038/sj.embor.7400073.

65. Silverman N, Zhou R, Erlich RL, Hunter M, Bernstein E, Schneider D, et al. Immune activation of NF-kappaB and JNK requires Drosophila TAK1.J Biol Chem. 2003;278(49):48928-34. https://doi.org/10.1074/jbc.M304802200.

66. Valanne S, Kleino A, Myllymäki H, Vuoristo J, Rämet M. lap2 is required for a sustained response in the Drosophila Imd pathway. Dev Comp Immunol. 2007;31(10):991-1001. https://doi.org/10.1016/j.dci.2007.01.004.

67. Short SM, Lazzaro BP. Reproductive status alters transcriptomic response to infection in female Drosophila melanogaster. G3 (Bethesda). 2013;3(5):827-40.

68. Reumer A, Bogaerts A, Van Loy T, Husson SJ, Temmerman L, Choi C, et al. Unraveling the protective effect of a Drosophila phosphatidylethanolamine-binding protein upon bacterial infection by means of proteomics. Dev Comp Immunol. 2009;33(11):1186-95. https://doi.org/10.1016/j.dci.2009.06.010.

69. Juneja P, Quinn A, Jiggins FM. Latitudinal clines in gene expression and cis-regulatory element variation in Drosophila melanogaster. BMC Genomics. 2016;17(1):981.

70. Watson FL, Püttmann-Holgado R, Thomas F, Lamar DL, Hughes M, Kondo M, et al. Extensive diversity of Ig-superfamily proteins in the immune system of insects. Science. 2005;309(5742):1874-8. https://doi.org/10.1126/science.1116887.

71. Valanne S, Myllymäki H, Kallio J, Schmid MR, Kleino A, Murumägi A, et al. Genome-wide RNA interference in Drosophila cells identifies $\mathrm{G}$ protein-coupled receptor kinase 2 as a conserved regulator of NF-kappaB signaling. J Immunol. 2010; 184(11):6188-98. https://doi.org/10.4049/jimmunol.1000261.

72. Broderick NA, Buchon N, Lemaitre B. Microbiota-induced changes in drosophila melanogaster host gene expression and gut morphology. MBio. 2014;5(3):e01117-4. https://doi.org/10.1128/mBio.01117-14.

73. Carpenter J, Hutter S, Baines JF, Roller J, Saminadin-Peter SS, Parsch J, et al. The transcriptional response of Drosophila melanogaster to infection with the sigma virus (Rhabdoviridae). PLoS One. 2009;4(8):e6838. https://doi.org/10.1371/ journal.pone.0006838.

74. Ullastres A, Petit N, González J. Exploring the phenotypic space and the evolutionary history of a natural mutation in Drosophila melanogaster. Mol Biol Evol. 2015;32(7):1800-14. https://doi.org/10.1093/molbev/msv061.

75. Costa E, Beltran S, Espinàs ML. Drosophila melanogaster SAP18 protein is required for environmental stress responses. FEBS Lett. 2011;585(2):275-80. https://doi.org/10.1016/j.febslet.2010.11.058.

76. Merenciano M, Ullastres A, de Cara MA, Barrón MG, González J. Multiple independent retroelement insertions in the promoter of a stress response gene have variable molecular and functional effects in Drosophila. PLoS Genet. 2016; 12(8):e1006249. https://doi.org/10.1371/journal.pgen.1006249.

77. Ayres JS, Freitag N, Schneider DS. Identification of Drosophila mutants altering defense of and endurance to Listeria monocytogenes infection. Genetics. 2008:178(3):1807-15. https://doi.org/10.1534/genetics.107.083782.

78. Kofler R, Betancourt AJ, Schlötterer C. Sequencing of pooled DNA samples (Pool-Seq) uncovers complex dynamics of transposable element insertions in Drosophila melanogaster. PLoS Genet. 2012;8(1):e1002487. https://doi.org/10.1371/ journal.pgen.1002487.

79. Ulvila J, Vanha-aho L-M, Kleino A, Vähä-Mäkilä M, Vuoksio M, Eskelinen S, et al. Cofilin regulator 14-3-3ろ is an evolutionarily conserved protein required for phagocytosis and microbial resistance. J Leukoc Biol. 2011;89(5):649-59.

80. Zhang Q, Zhang L, Gao X, Qi S, Chang Z, Wu Q. DIP1 plays an antiviral role against DCV infection in Drosophila melanogaster. Biochem Biophys Res Commun. 2015;460(2):222-6. https://doi.org/10.1016/j.bbrc.2015.03.013.

81. van Rij RP, Saleh MC, Berry B, Foo C, Houk A, Antoniewski C, et al. The RNA silencing endonuclease Argonaute 2 mediates specific antiviral immunity in Drosophila melanogaster. Genes Dev. 2006;20(21):2985-95.

82. Fukuyama H, Verdier Y, Guan Y, Makino-Okamura C, Shilova V, Liu X, et al. Landscape of protein-protein interactions in Drosophila immune deficiency signaling during bacterial challenge. Proc Natl Acad Sci U S A. 2013;110(26):10717-22. https://doi.org/10.1073/pnas.1304380110.

83. Berkey CD, Blow N, Watnick PI. Genetic analysis of Drosophila melanogaster susceptibility to intestinal Vibrio cholerae infection. Cell Microbiol. 2009;11(3):461-74. https://doi.org/10.1111/j.1462-5822.2008.01267.x.

84. Brown AE, Baumbach J, Cook PE, Ligoxygakis P. Short-term starvation of immune deficient Drosophila improves survival to gram-negative bacterial infections. PLoS One. 2009;4(2):e4490.

85. Christofi T, Apidianakis Y. Drosophila immune priming against Pseudomonas aeruginosa is short-lasting and depends on cellular and humoral immunity. F1000Res. 2013;2:76.

86. Cornwell WD, Kirkpatrick RB. Cactus-independent nuclear translocation of Drosophila RELISH. J Cell Biochem. 2001;82(1): 22-37. https://doi.org/10.1002/jcb.1144.

87. Gobert V, Gottar M, Matskevich AA, Rutschmann S, Royet J, Belvin M, et al. Dual activation of the Drosophila toll pathway by two pattern recognition receptors. Science. 2003;302(5653):2126-30. https://doi.org/10.1126/science.1 085432.

88. Rutschmann S, Jung AC, Hetru C, Reichhart JM, Hoffmann JA, Ferrandon D. The Rel protein DIF mediates the antifungal but not the antibacterial host defense in Drosophila. Immunity. 2000;12(5):569-80. https://doi.org/10.1016/S1074-7613 (00)80208-3.

89. Rutschmann S, Kilinc A, Ferrandon D. Cutting edge: the toll pathway is required for resistance to gram-positive bacterial infections in Drosophila. J Immunol. 2002;168(4):1542-6.

90. Clark RI, Tan SW, Péan CB, Roostalu U, Vivancos V, Bronda K, et al. MEF2 is an in vivo immune-metabolic switch. Cell. 2013;155(2):435-47. https://doi.org/10.1016/j.cell.2013.09.007.

91. Arbouzova NI, Bach EA, Zeidler MP. Ken \& barbie selectively regulates the expression of a subset of Jak/STAT pathway target genes. Curr Biol. 2006;16(1):80-8.

92. Wittkopp PJ, Haerum BK, Clark AG. Evolutionary changes in cis and trans gene regulation. Nature. 2004;430(6995):85-8. 
93. Almlöf JC, Lundmark P, Lundmark A, Ge B, Maouche S, Göring HH, et al. Powerful identification of cis-regulatory SNPs in human primary monocytes using allele-specific gene expression. PLoS One. 2012;7(12):e52260.

94. Hawkins JS, Delgado V, Feng L, Carlise M, Dooner HK, Bennetzen JL. Variation in allelic expression associated with a recombination hotspot in Zea mays. Plant J. 2014;79(3):375-84. https://doi.org/10.1111/tpj.12537.

95. Tung J, Akinyi MY, Mutura S, Altmann J, Wray GA, Alberts SC. Allele-specific gene expression in a wild nonhuman primate population. Mol Ecol. 2011;20(4):725-39. https://doi.org/10.1111/j.1365-294X.2010.04970.X.

96. Von Korff M, Radovic S, Choumane W, Stamati K, Udupa SM, Grando S, et al. Asymmetric allele-specific expression in relation to developmental variation and drought stress in barley hybrids. Plant J. 2009;59(1):14-26. https://doi.org/1 0.1111/j.1365-313X.2009.03848.x.

97. Osada N, Miyagi R, Takahashi A. Cis- and trans-regulatory effects on gene expression in a natural population of Drosophila melanogaster. Genetics. 2017;206(4):2139-48.

98. Glaser-Schmitt A, Parsch J. Functional characterization of adaptive variation within a cis-regulatory element influencing Drosophila melanogaster growth. PLoS Biol. 2018;16(1):e2004538. https://doi.org/10.1371/journal.pbio.2004538.

99. Lee YC. The Role of piRNA-mediated epigenetic silencing in the population dynamics of transposable elements in Drosophila melanogaster. PLoS Genet. 2015;11(6):e1005269. https://doi.org/10.1371/journal.pgen.1005269.

100. Lee YCG, Karpen GH. Pervasive epigenetic effects of Drosophila euchromatic transposable elements impact their evolution. Elife. 2017;6. https://doi.org/10.7554/eLife.25762.

101. Yin H, Sweeney S, Raha D, Snyder M, Lin H. A high-resolution whole-genome map of key chromatin modifications in the adult Drosophila melanogaster. PLoS Genet. 2011;7(12):e1002380.

102. Dantoft W, Lundin D, Esfahani SS, Engström Y. The POU/Oct Transcription factor Pdm1/nub is necessary for a beneficial gut microbiota and normal lifespan of Drosophila. J Innate Immun. 2016;8(4):412-26. https://doi.org/10.1159/000446368.

103. Ryu JH, Kim SH, Lee HY, Bai JY, Nam YD, Bae JW, et al. Innate immune homeostasis by the homeobox gene caudal and commensal-gut mutualism in Drosophila. Science. 2008;319(5864):777-82. https://doi.org/10.1126/science.1149357.

104. Junell A, Uvell H, Davis MM, Edlundh-Rose E, Antonsson A, Pick L, et al. The POU transcription factor Drifter/Nentral veinless regulates expression of Drosophila immune defense genes. Mol Cell Biol. 2010;30(14):3672-84. https://doi.org/1 0.1128/MCB.00223-10.

105. Reed DE, Huang XM, Wohlschlegel JA, Levine MS, Senger K. DEAF-1 regulates immunity gene expression in Drosophila. Proc Natl Acad Sci U S A. 2008;105(24):8351-6. https://doi.org/10.1073/pnas.0802921105.

106. Thurmond J, Goodman JL, Strelets VB, Attrill H, Gramates LS, Marygold SJ, et al. FlyBase 2.0: the next generation. Nucleic Acids Res. 2019;47(D1):D759-D65. https://doi.org/10.1093/nar/gky1003.

107. Obbard DJ, Welch JJ, Kim KW, Jiggins FM. Quantifying adaptive evolution in the Drosophila immune system. PLoS Genet. 2009:5(10):e1000698. https://doi.org/10.1371/journal.pgen.1000698.

108. Early AM, Arguello JR, Cardoso-Moreira M, Gottipati S, Grenier JK, Clark AG. Survey of global genetic diversity within the Drosophila immune system. Genetics. 2017;205(1):353-66.

109. Belmonte RL, Corbally MK, Duneau DF, Regan JC. Sexual dimorphisms in innate immunity and responses to infection in Drosophila melanogaster. Front Immunol. 2019;10:3075.

110. Cridland JM, Thornton KR, Long AD. Gene expression variation in Drosophila melanogaster due to rare transposable element insertion alleles of large effect. Genetics. 2015;199(1):85-93. https://doi.org/10.1534/genetics.114.170837.

111. Guio L, Vieira C, González J. Stress affects the epigenetic marks added by natural transposable element insertions in Drosophila melanogaster. Sci Rep. 2018;8(1):12197. https://doi.org/10.1038/s41598-018-30491-w.

112. Kouzarides T. Chromatin modifications and their function. Cell. 2007;128(4):693-705. https://doi.org/10.1016/j.cell.2007.02.005.

113. Halfon MS. Studying transcriptional enhancers: the founder fallacy, validation creep, and other biases. Trends Genet. 2019;35(2):93-103. https://doi.org/10.1016/j.tig.2018.11.004.

114. Spitz F, Furlong EE. Transcription factors: from enhancer binding to developmental control. Nat Rev Genet. 2012;13(9): 613-26. https://doi.org/10.1038/nrg3207.

115. Halfon MS. Silencers, enhancers, and the multifunctional regulatory genome. Trends Genet. 2020;36(3):149-51. https:// doi.org/10.1016/j.tig.2019.12.005.

116. Dao LTM, Spicuglia S. Transcriptional regulation by promoters with enhancer function. Transcription. 2018;9(5):307-14.

117. Andersson R, Gebhard C, Miguel-Escalada I, Hoof I, Bornholdt J, Boyd M, et al. An atlas of active enhancers across human cell types and tissues. Nature. 2014;507(7493):455-61. https://doi.org/10.1038/nature12787.

118. Kwasnieski JC, Fiore C, Chaudhari HG, Cohen BA. High-throughput functional testing of ENCODE segmentation predictions. Genome Res. 2014;24(10):1595-602.

119. Wertheim B, Kraaijeveld AR, Hopkins MG, Walther Boer M, Godfray HC. Functional genomics of the evolution of increased resistance to parasitism in Drosophila. Mol Ecol. 2011;20(5):932-49. https://doi.org/10.1111/j.1365-294X.2010.04 911.x.

120. Magwire MM, Bayer F, Webster CL, Cao C, Jiggins FM. Successive increases in the resistance of Drosophila to viral infection through a transposon insertion followed by a Duplication. PLoS Genet. 2011;7(10):e1002337. https://doi.org/1 0.1371/journal.pgen.1002337.

121. Telenti A, di lulio J. Regulatory genome variants in human susceptibility to infection. Hum Genet. 2020;139(6-7):759-68. https://doi.org/10.1007/s00439-019-02091-9.

122. Wang L, Rishishwar L, Jordan IK, Mariño-Ramírez L. Human population-specific gene expression and transcriptional network modification with polymorphic transposable elements. Nucleic Acids Res. 2016;45(5):2318-28.

123. Mackay TF, Richards S, Stone EA, Barbadilla A, Ayroles JF, Zhu D, et al. The Drosophila melanogaster Genetic Reference Panel. Nature. 2012;482(7384):173-8. https://doi.org/10.1038/nature10811.

124. Lack JB, Cardeno CM, Crepeau MW, Taylor W, Corbett-Detig RB, Stevens KA, et al. The Drosophila genome nexus: a population genomic resource of 623 Drosophila melanogaster genomes, including 197 from a single ancestral range population. Genetics. 2015;199(4):1229-41. https://doi.org/10.1534/genetics.115.174664.

125. Port F, Bullock SL. Augmenting CRISPR applications in Drosophila with tRNA-flanked sgRNAs. Nat Methods. 2016;13(10): 852-4. https://doi.org/10.1038/nmeth.3972.

126. Kapitonov W, Jurka J. Molecular paleontology of transposable elements in the Drosophila melanogaster genome. Proc Natl Acad Sci U S A. 2003;100(11):6569-74. 
127. Sackton TB, Kulathinal RJ, Bergman CM, Quinlan AR, Dopman EB, Carneiro M, et al. Population genomic inferences from sparse high-throughput sequencing of two populations of Drosophila melanogaster. Genome Biol Evol. 2009;1:449-65.

128. Singh ND, Petrov DA. Rapid sequence turnover at an intergenic locus in Drosophila. Mol Biol Evol. 2004;21(4):670-80. https://doi.org/10.1093/molbev/msh060.

129. Fiston-Lavier AS, Singh ND, Lipatov M, Petrov DA. Drosophila melanogaster recombination rate calculator. Gene. 2010; 463(1-2):18-20. https://doi.org/10.1016/j.gene.2010.04.015.

130. Comeron JM, Ratnappan R, Bailin S. The many landscapes of recombination in Drosophila melanogaster. PLoS Genet. 2012;8(10):e1002905. https://doi.org/10.1371/journal.pgen.1002905.

131. Charlesworth B, Morgan MT, Charlesworth D. The effect of deleterious mutations on neutral molecular variation. Genetics. 1993;134(4):1289-303.

132. Hill WG, Robertson A. The effect of linkage on limits to artificial selection. Genet Res. 1966;8(3):269-94. https://doi.org/1 $0.1017 / 50016672300010156$.

133. Hudson RR, Kaplan NL. Deleterious background selection with recombination. Genetics. 1995;141(4):1605-17. https://doi. org/10.1093/genetics/141.4.1605.

134. Smith JM, Haigh J. The hitch-hiking effect of a favourable gene. Genet Res. 1974;23(1):23-35. https://doi.org/10.1017/ S0016672300014634.

135. Barrón MG, Fiston-Lavier AS, Petrov DA, González J. Population genomics of transposable elements in Drosophila. Annu Rev Genet. 2014;48:561-81.

136. Castellano D, Coronado-Zamora M, Campos JL, Barbadilla A, Eyre-Walker A. Adaptive evolution is substantially impeded by Hill-Robertson interference in Drosophila. Mol Biol Evol. 2016;33(2):442-55. https://doi.org/10.1093/molbev/msv236.

137. Ye J, Coulouris G, Zaretskaya I, Cutcutache I, Rozen S, Madden TL. Primer-BLAST: a tool to design target-specific primers for polymerase chain reaction. BMC Bioinformatics. 2012;13(1):134. https://doi.org/10.1186/1471-2105-13-134.

138. González J, Lenkov K, Lipatov M, Macpherson JM, Petrov DA. High rate of recent transposable element-induced adaptation in Drosophila melanogaster. PLoS Biol. 2008;6(10):e251.

139. Neyen C, Bretscher AJ, Binggeli O, Lemaitre B. Methods to study Drosophila immunity. Methods. 2014;68(1):116-28.

140. Vallet-Gely I, Novikov A, Augusto L, Liehl P, Bolbach G, Péchy-Tarr M, et al. Association of hemolytic activity of Pseudomonas entomophila, a versatile soil bacterium, with cyclic lipopeptide production. Appl Environ Microbiol. 2010; 76(3):910-21.

141. Bustin SA, Benes V, Garson JA, Hellemans J, Huggett J, Kubista M, et al. The MIQE guidelines: minimum information for publication of quantitative real-time PCR experiments. Clin Chem. 2009;55(4):611-22. https://doi.org/10.1373/clinchem.2 008.112797

142. Ràmia M, Librado P, Casillas S, Rozas J, Barbadilla A. PopDrowser: the population Drosophila browser. Bioinformatics. 2012;28(4):595-6. https://doi.org/10.1093/bioinformatics/btr691.

143. Junqueira AC, Azeredo-Espin AM, Paulo DF, Marinho MA, Tomsho LP, Drautz-Moses DI, et al. Large-scale mitogenomics enables insights into Schizophora (Diptera) radiation and population diversity. Sci Rep. 2016;6(1):21762. https://doi.org/1 $0.1038 / \mathrm{srep} 21762$.

144. Obbard DJ, Jiggins FM, Halligan DL, Little TJ. Natural selection drives extremely rapid evolution in antiviral RNAi genes. Curr Biol. 2006;16(6):580-5. https://doi.org/10.1016/j.cub.2006.01.065.

145. Wittkopp PJ, Kalay G. Cis-regulatory elements: molecular mechanisms and evolutionary processes underlying divergence. Nat Rev Genet. 2011;13(1):59-69. https://doi.org/10.1038/nrg3095.

146. Benjamini $Y$, Hochberg $Y$. Controlling the false discovery rate: a practical and powerful approach to multiple testing. J R Stat Soc Ser B (Methodological). 1995;57(1):289-300. https://doi.org/10.1111/j.2517-6161.1995.tb02031.x.

147. Brizuela BJ, Elfring L, Ballard J, Tamkun JW, Kennison JA. Genetic analysis of the brahma gene of Drosophila melanogaster and polytene chromosome subdivisions 72AB. Genetics. 1994;137(3):803-13. https://doi.org/10.1093/ genetics/137.3.803.

148. Adams MD, Celniker SE, Holt RA, Evans CA, Gocayne JD, Amanatides PG, et al. The genome sequence of Drosophila melanogaster. Science. 2000;287(5461):2185-95. https://doi.org/10.1126/science.287.5461.2185.

149. Celniker SE, Wheeler DA, Kronmiller B, Carlson JW, Halpern A, Patel S, et al. Finishing a whole-genome shotgun: release 3 of the Drosophila melanogaster euchromatic genome sequence. Genome Biol. 2002;3(12):RESEARCH0079.

150. Hoskins RA, Nelson CR, Berman BP, Laverty TR, George RA, Ciesiolka L, et al. A BAC-based physical map of the major autosomes of Drosophila melanogaster. Science. 2000;287(5461):2271-4. https://doi.org/10.1126/science.287.5461.2271.

151. Bischof J, Maeda RK, Hediger M, Karch F, Basler K. An optimized transgenesis system for Drosophila using germ-linespecific phic31 integrases. Proc Natl Acad Sci U S A. 2007;104(9):3312-7. https://doi.org/10.1073/pnas.0611511104.

\section{Publisher's Note}

Springer Nature remains neutral with regard to jurisdictional claims in published maps and institutional affiliations.

\section{Ready to submit your research? Choose BMC and benefit from:}

- fast, convenient online submission

- thorough peer review by experienced researchers in your field

- rapid publication on acceptance

- support for research data, including large and complex data types

- gold Open Access which fosters wider collaboration and increased citations

- maximum visibility for your research: over 100M website views per year

At $\mathrm{BMC}$, research is always in progress.

Learn more biomedcentral.com/submissions 